\title{
Unacylated ghrelin and AZP531 suppress the 3D growth of breast cancers
}

\author{
CheukMan C. Au ${ }^{1,2,3}$, John B. Furness ${ }^{4}$, Kara Britt ${ }^{5,6}$, Sofya Oshchepkova ${ }^{1}$, Heta Ladumor ${ }^{1,7}$, Kai Ying Soo², Brid Callaghan ${ }^{4}$, Céline Gérard ${ }^{2}$ \\ Giorgio Inghirami ${ }^{8}$, Vivek Mittal ${ }^{9}$, Yufeng Wang ${ }^{10}$, Xin-Yun Huang $^{10}$, Jason A. Spector ${ }^{11}$, Eleni Andreopoulou ${ }^{1}$, Paul Zumbo ${ }^{10,12}$, Doron \\ Betel $^{1,13}$, Lukas E. Dow ${ }^{1}$, Kristy A. Brown ${ }^{1,2,3^{*}}$
}

\begin{abstract}
Breast cancer is the most common type of cancer in women and notwithstanding important therapeutic advances, it remains the second leading cause of cancer-related death in the US. Despite extensive research relating to the hormone ghrelin, responsible for the stimulation of growth hormone release and appetite, little is known of the effects of its unacylated form, especially in cancer. One major area of research relates to its reported effects to increase insulin sensitivity in diabetics, this being the basis for the development of unacylated ghrelin analog, AZP531 or livoletide, now in clinical trials for the treatment of PraderWilli Syndrome. The mechanism of action of unacylated ghrelin is largely uncharacterized, in any system, because it does not bind to or activate the cognate ghrelin receptor, GHSR1a. The present study aimed to characterize effects of unacylated ghrelin on breast cancer cells, define its mechanism of action, and explore the therapeutic potential of unacylated ghrelin or analog AZP531. We report potent effects of unacylated ghrelin, at picomolar doses, on the growth of breast cancer cells, dependent on 3D culture and activation of Gai. Suppression of MAPK signaling by unacylated ghrelin leads to cell cycle arrest and apoptosis. AZP531 also suppresses the growth of breast cancer cells in vitro and in xenografts, and may be a novel approach for the safe and effective treatment of breast cancer.
\end{abstract}

Breast cancer is the most commonly diagnosed cancer in women and second only to lung cancer in terms of mortality (Noone et al., 2018). The majority of breast cancers occur after menopause and are hormone receptor positive, and in these women, first line therapy usually involves endocrine therapy, e.g. aromatase inhibitors or tamoxifen (Reinert and Barrios, 2015). Despite the efficacy of endocrine therapy, a number of women experience severe and debilitating side effects due to the global inhibition of estrogen biosynthesis or action, and some will cease the use of their potentially life-saving treatment (Lonning and Eikesdal, 2013). A proportion of women will also be resistant to treatment or develop resistance over time, and some will have tumors that cannot be treated with targeted therapies, i.e. triple negative breast cancers (TNBCs). Aggressive breast cancers are often associated with activation of RAS/MAPK signaling (Giltnane and Balko, 2014; Santen et al., 2002), despite only a minority carrying a mutation in these genes (Tilch et al., 2014). The prognosis for these patients is poor and hence, there is a need to identify alternative treatments that are safe and effective.

The unacylated form of ghrelin is closely related to the appetite-stimulating hormone ghrelin. However, because it lacks octanoylation, it does not bind to the cognate ghrelin receptor, GHSR1a. Initially, unacylated ghrelin was believed to be produced as a by-product of ghrelin gene expression. However, recent studies have established an important role for this peptide hormone in regulating energy homeostasis, including reducing fat mass, improving insulin sensitivity and decreasing fasting glucose levels (Benso et al., 2012; Zhang et al., 2008). An unacylated ghrelin analog, AZP531 (levolitide), is currently in clinical trials for the treatment of Prader-Willi Syndrome and type II diabetes (Allas et al., 2016). AZP531 has an established safety profile and better pharmacokinetic properties than unacylated ghrelin (Allas et al., 2016). The receptor for unacylated ghrelin is currently unknown (Au et al., 2016) and consequently, there is an important gap in our understanding of the mechanisms mediating its effects.

We have previously demonstrated that unacylated ghrelin has activity in non-cancer tissue, including adipose stromal cells, where it suppresses the expression of the estrogen-biosynthetic enzyme aromatase, and breast adipose tissue macrophages, where it inhibits the production of inflammatory mediators (Au et al., 2017; Docanto et al., 2014). Here, we show that the unacylated form of ghrelin is a potent suppressor of breast cancer cell growth, independent of effects on the stroma, and provide a novel mechanism of action via activation of Gai, suppression of cAMP production, and inhibition of MAPK and Akt signaling. Importantly, the potent effects of unacylated ghrelin are dependent on growth of cells in 3D within a relevant extracellular matrix (ECM). Our findings, and that of others, suggest that tumor cell culture context affects

1Department of Medicine, Weill Cornell Medicine, New York, NY, 10065, USA. 2Centre for Cancer Research, Hudson Institute for Medical Research, Clayton, VIC, 3168, Australia. 3Department of Molecular and Translational Sciences, Monash University, Clayton, VIC, 3800, Australia. 4Department of Anatomy \& Neuroscience, University of Melbourne, Parkville, VIC, 3010, Australia 5Peter MacCallum Cancer Centre, Melbourne, VIC, 3000, Australia 6Sir Peter MacCallum Department of Oncology, University of Melbourne, VIC 3000, Australia 7Weill Cornell Medicine - Qatar, Doha, Qatar 8Department of Pathology, Weill Cornell Medical College, New York, NY, 10065, USA 9Department of Cardiothoracic Surgery, Department of Cell and Developmental Biology, Neuberger Berman Lung Cancer Center, Weill Cornell Medicine, New York, NY10065, USA 10Department of Physiology and Biophysics, Weill Cornell Medical College of Cornell University, New York, NY 10065, United States 11Department of Surgery, Weill Cornell Medicine, New York, NY, 10065, USA 12Applied Bioinformatics Core, Weill Cornell Medical College, New York, NY, 10021, USA 13Institute for Computational Biomedicine, Weill Cornell Medical College, New York, NY, 10021, USA 
bioRxiv preprint doi: https://doi.org/10.1101/2020.01.22.915744; this version posted January 23, 2020. The copyright holder for this preprint (which was not certified by peer review) is the author/funder, who has granted bioRxiv a license to display the preprint in perpetuity. It is made available under aCC-BY-NC-ND 4.0 International license.

Au et al, Unacylated ghrelin and AZP531 suppress the 3D growth of breast cancers - preprint

A

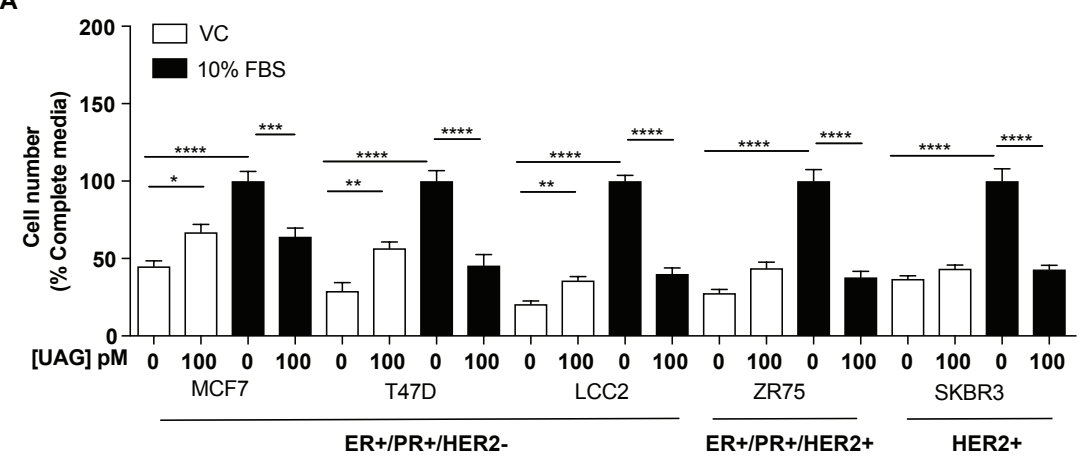

c

C $\quad{ }^{150} \square$ VC $10 \%$ FBS

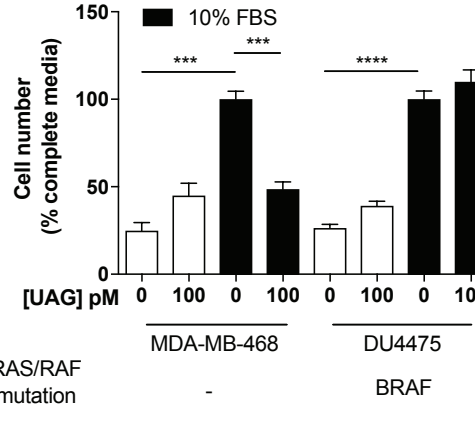

Morphology Basal

E

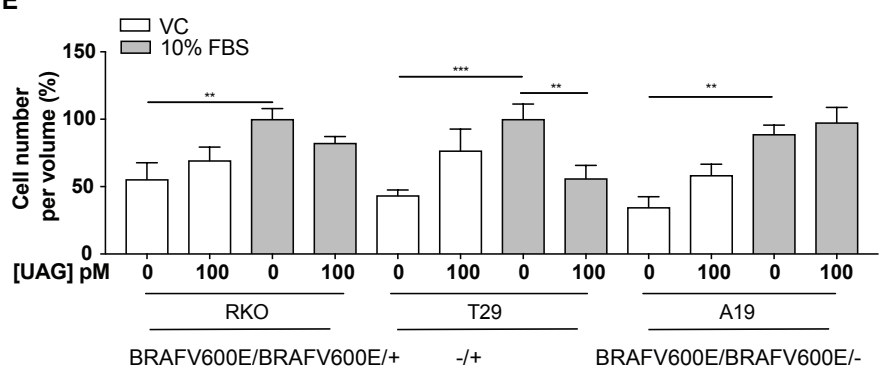

Basal Mesenchymal Mesenchymal Mesenchymal
B

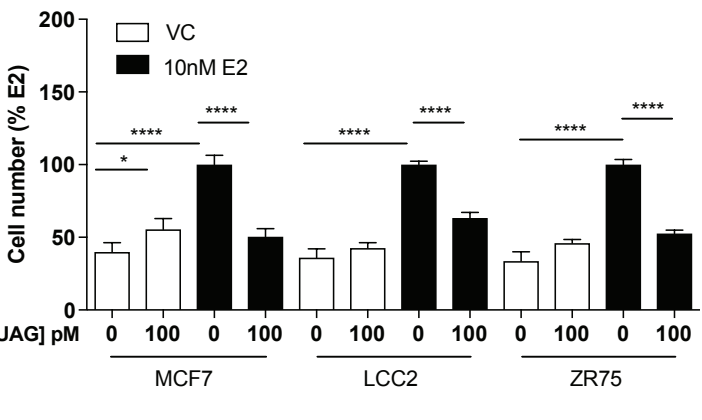

D

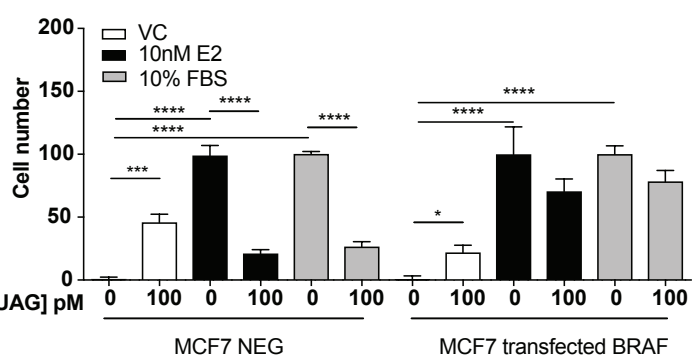

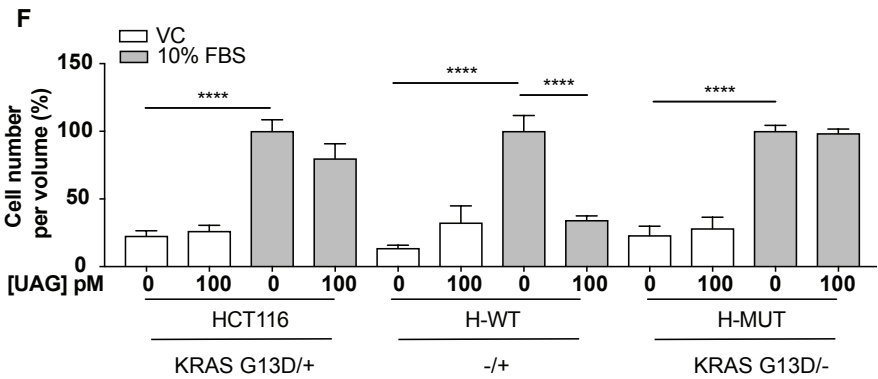

Figure 1. Unacylated ghrelin (UAG) inhibits the growth of breast cancer cells dependent on RAS/RAF mutation status. (A, C) UAG (100pM) inhibits the growth of a panel of breast cancer cell lines under serum-stimulated conditions or (B) ER+ breast cancer cell lines in the presence of estradiol (10nM). (C) UAG (100pM) suppresses cell growth of basal-like and mesenchymal-like TNBC breast cancer cell lines that are WT for BRAF and KRAS. Effects of UAG are abrogated in (D) BRAF-transfected MCF7 cells, and (E) BRAF- and (F) KRAS-mutated colon cancer cells. Loss of mutated alleles of BRAF or KRAS sensitizes cells to the effect of UAG. Data represent mean \pm SEM with $n \geq 3$. Experiment was repeated at least twice. UAG: unacylated ghrelin; VC: vehicle control; FBS: fetal bovine serum; E2: estradiol

response to therapy and that many translational failures may have resulted from the inappropriate model systems used to date (Tian et al., 2015). It also suggests that others may have overlooked many effective therapies due to a lack of response in $2 \mathrm{D}$ cultures. We therefore believe that unacylated ghrelin is a prototypic 3D-specific breast cancer cell therapeutic and that characterizing its mechanism of action in a biologically relevant ECM will lead to a better understanding of how the tumor microenvironment affects response to therapy. We also demonstrate consistent effects in patient-derived breast cancer cells and breast cancer xenografts in preclinical models, where both unacylated ghrelin and AZP531 are effective at causing growth inhibition.

\section{RESULTS}

\section{Unacylated ghrelin inhibits the 3D growth of breast cancer cells}

Previous studies examining the effect of ghrelin and unacylated ghrelin on the growth of breast cancer cells showed little activity at doses below $1 \mu \mathrm{M}$ (Cassoni et al., 2001). Considering the increasingly acknowledged role of the ECM in dictating biology of tumors in vivo, including aggressiveness and response to treatment, we sought to examine the effect of ghrelin and more importantly, unacylated ghrelin, in 3D cultures of breast cancer cells. Although both are hypothesized to bind alternate ghrelin receptors, beneficial effects on energy homeostasis have only been reported for unacylated ghrelin 
bioRxiv preprint doi: https://doi.org/10.1101/2020.01.22.915744; this version posted January 23, 2020. The copyright holder for this preprint (which was not certified by peer review) is the author/funder, who has granted bioRxiv a license to display the preprint in perpetuity. It is made available under aCC-BY-NC-ND 4.0 International license.

Au et al, Unacylated ghrelin and AZP531 suppress the 3D growth of breast cancers - preprint

- likely due to ghrelin stimulating insulin resistance via its cognate receptor. One hundred picomolar of either ghrelin and unacylated ghrelin were found to suppress the growth of MCF7 and MDA-MB-468 breast cancer cells when grown in 3D in matrigel (Figure. S1G). The dependence on 3D culture was further examined for unacylated ghrelin, where treatment with $100 \mathrm{pM}$ resulted in suppression of cell growth in matrigel and collagen, but not in 2D (Figure. S1 A and B). At this dose, no effects on MDA-MB-231 cell growth were observed in either 2D or 3D cultures (Figure. S1C). Inhibition of MCF7 and MDA-MB-468 cell growth was observed at $10^{-18}-10^{-10} \mathrm{M}$, with maximal effects observed at picomolar doses (Figure. S1D and E). The degree of inhibition is directly related to the degree of growth stimulation induced by serum or estradiol. Again, no significant effect was observed in MDA-MB-231 cells (Figure. S1F). To gain insights into the breadth of effects
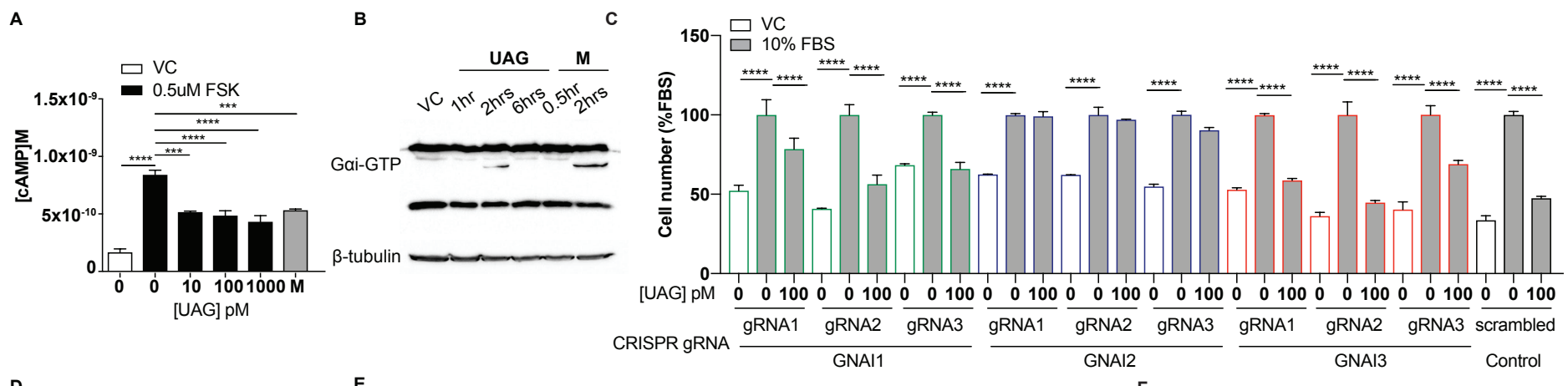

D

E

MCF7

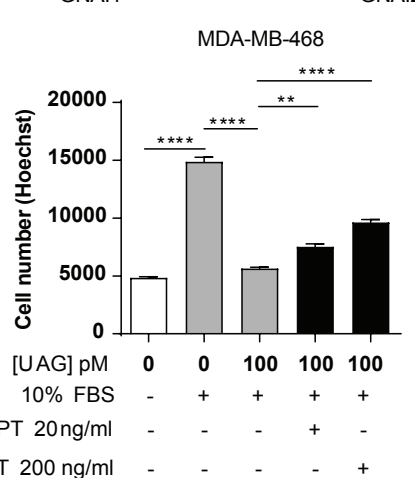

$\mathbf{F}$
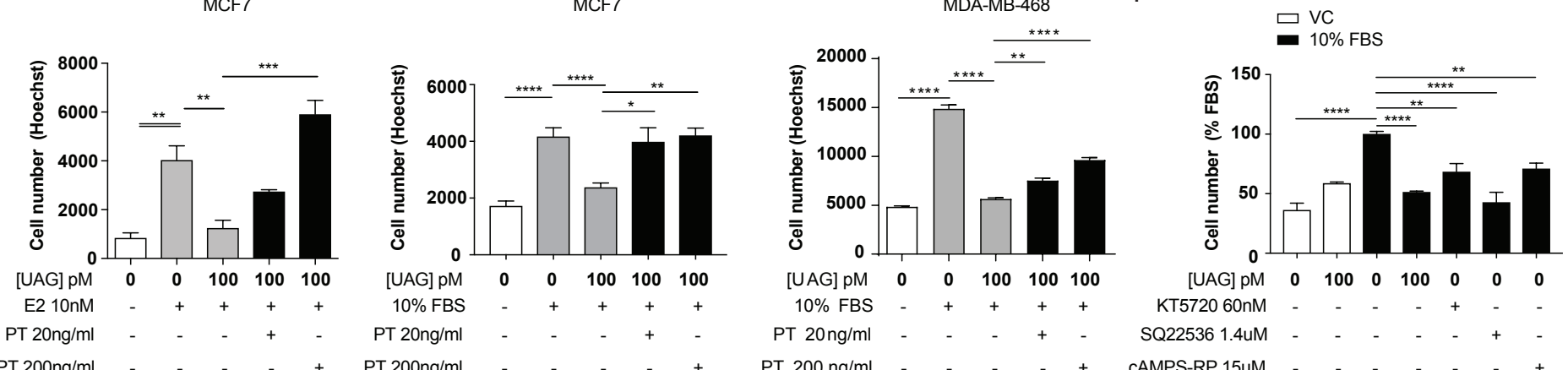

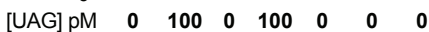

KT5720 60nM

SQ22536 1.4UM

cAMPS-RP 15uM

G
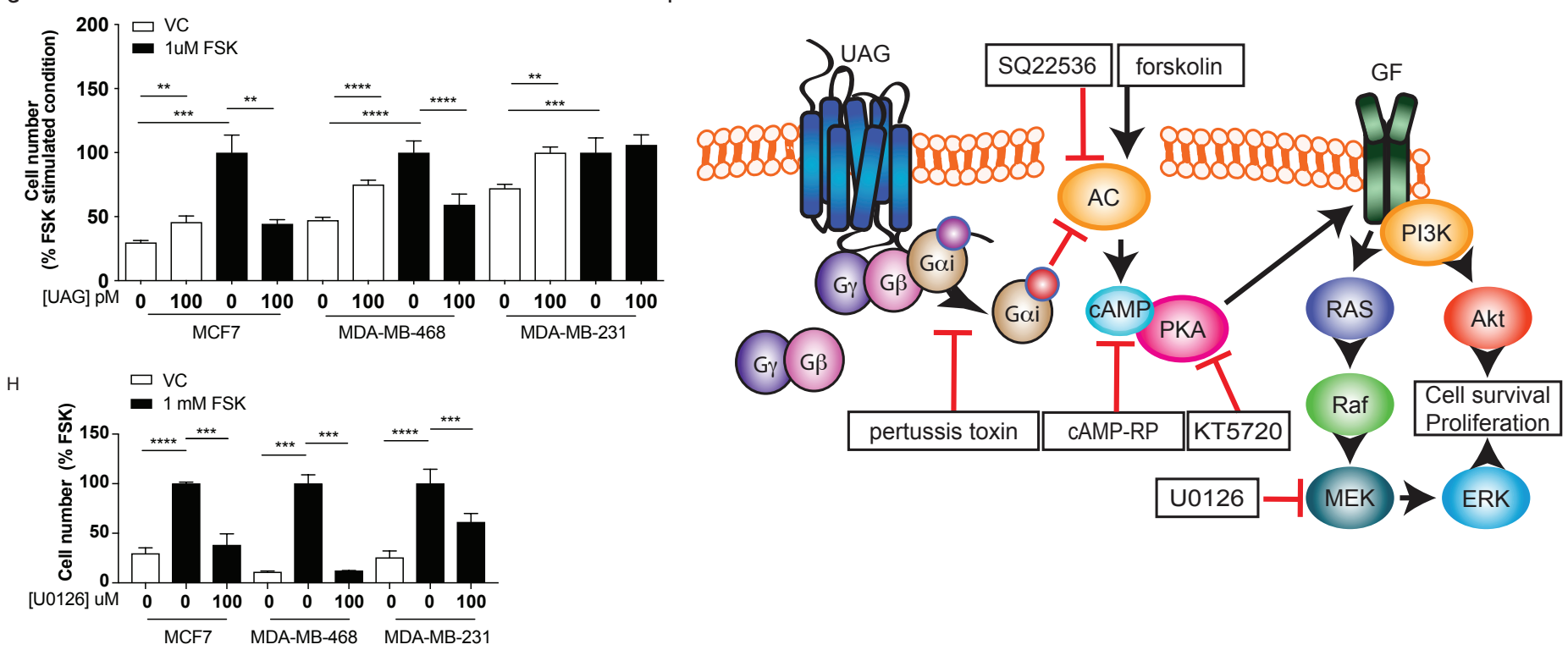

Figure 2. Unacylated ghrelin (UAG) suppresses breast cancer cell growth via Gai-dependent inhibition of cAMP formation. (A) UAG (10-1000pM) inhibits the forskolin-stimulated production of cAMP in MCF7 cells. (B) UAG (100pM) mediates its effects via activation of Gai. (C) UAG (100pM) suppresses the growth of CRISPR GNAI1 and GNAI3 KO cells, but not GNAI2 KO MCF7 cells, suggesting GNAI2-coupled GPCR-mediated effects. Suppression of (D) estradiol- or (E) serum-stimulated breast cancer cell growth with UAG (100pM) is prevented in the presence of Gai inhibitor, pertussis toxin (20ng/ml, 200ng/ $\mathrm{ml}$ ). (F) PKA or adenylyl cyclase inhibitors, or a cAMP antagonist also suppresses MCF7 breast cancer cell growth. (G) UAG (100pM) inhibits the forskolinstimulated growth of MCF7 and MDA-MB-468 cells, but not MDA-MB-231. (H) U0126 (MEK inhibitor) inhibits the forskolin-stimulated growth of MCF7, MDA-MB-468 and MDA-MB-231 cells. (I) A model summarizing the putative mechanism of action of UAG in breast cancer cells. Data represent mean \pm SEM with $n \geq 3$. Experiments were repeated at least twice. UAG: unacylated ghrelin; VC: vehicle control; FBS: fetal bovine serum; E2: estradiol; PT: pertussis toxin; M: melatonin; FSK: forskolin 
of unacylated and potential predictors of response, the effect of $100 \mathrm{pM}$ unacylated ghrelin was tested in a panel of breast cancer cell lines, including ER+/PR+/HER2- (MCF7, T47D), $\mathrm{ER}+/ \mathrm{PR}+/ \mathrm{HER} 2+$ (ZR-75), HER2+ (SKBR3), TNBC (MDAMB-468, DU4475, MDA-MB-157, Hs578T, MDA-MB-231), and tamoxifen-resistant (LCC2) cells (Figure 1A-C). Under serum-free conditions, unacylated ghrelin stimulated or had no effect on the growth of breast cancer cells. In the presence of serum, unacylated ghrelin significantly inhibited the growth of all breast cancer cells examined except for three of the TNBC cell lines (DU4475, Hs578T and MDA-MB-231). Unacylated ghrelin also suppressed the estradiol-stimulated growth of ER+ breast cancer cells (Figure 1B). Responsive cells included those having mutations in PTEN and PI3K, while resistant cell lines carried mutations in BRAF, HRAS and/or KRAS (Figure 1C; Table 1). To test whether these mutations confer resistance to treatment, the effects of unacylated ghrelin were examined in BRAFV600E-transfected MCF7 cells or colon cancer cells (RKO, HCT116) that carry mutations in BRAF or KRAS, respectively. Transient transfection of MCF7 cells with mutant BRAF led to resistance to unacylated ghrelin treatment in estradiol- and serum-stimulated cells (Figure 1D). Unacylated ghrelin had no effect on the growth of RKO and HCT116 cells (Figure 1D and E). However, loss of the mutant alleles for BRAF or KRAS led to sensitization of RKO and HCT116 cells, respectively. Loss of the wild type allele had no significant effect. Binding of Cy3-labeled unacylated ghrelin to responsive and non-responsive cells (Figure $\mathrm{S} 1 \mathrm{H}$ ) suggests that resistance is not due to lack of binding or receptor expression.

\section{Unacylated ghrelin suppresses breast cancer cell growth via Gai-dependent inhibition of cAMP formation}

Unacylated ghrelin does notbind to the cognateghrelin receptor GHSR1a and the receptor for unacylated ghrelin, believed to be an alternate ghrelin receptor, is currently unknown, but hypothesized to be a GPCR. Effects of unacylated ghrelin on second messenger systems were assessed by measuring the formation of CAMP and the release of intracellular calcium in MCF7 cells (Figure 2A and Figure S2A). Unacylated ghrelin significantly suppressed the formation of CAMP, but had no effect on intracellular calcium release. Effects on cAMP suggest a Gai-dependent mechanism. Activation of Gai by unacylated ghrelin was observed after 2-hr treatment, as measured by pull-down of GTP-bound Gai (Figure 2B). To test dependence of growth inhibitory effects of unacylated ghrelin on Gai, 3D growth assays were performed in cells where the Gai-encoding gene, guanine nucleotide-binding protein, alpha subunit (GNAI), was knocked out (CRISPR; Figure 2C) or in the presence of Gai inhibitor pertussis toxin (Figure 2D and 2E). There are three Gai encoding genes in mammalian cells (GNAI1, GNAI2, and GNAI3). Unacylated ghrelin had no effect on cells lacking Ga I subunit 2 (GNAI2), whereas the growth of cells was significantly suppressed where G $\alpha$ I subunit 1 (GNAI1) and G $\alpha$ I subunit 3 (GNAI3) were targeted. GNAI2 was also found to be required for unacylated ghrelin activity in MDA-MB-468 cells (Figure
S2D). Effects of unacylated ghrelin were also attenuated in cells treated with pertussis toxin, in the presence of estradiol or serum. To determine whether inhibition of cAMP is sufficient to suppress the serum-stimulated growth of breast cancer cells, MCF7 and MDA-MB-468 cells were treated with adenylyl cyclase and PKA inhibitors, SQ22536 and KT5720, and CAMP antagonist, CAMPS-RP (Figure 2F; Figure S2B). Inhibition of CAMP formation and PKA led to a significant reduction in cell number. Effects of cAMP on cell growth were then examined in cells treated with adenylyl cyclase stimulator, forskolin (Figure 2G). Forskolin stimulated the growth of MCF7, MDA-MB-468 and MDA-MB-231 cells, and similar to effects of unacylated ghrelin in serum- or estradiolstimulated conditions, unacylated ghrelin suppressed the forskolin-mediated induction of MCF7 and MDA-MB-468 cell growth, but not MDA-MB-231. As resistance to unacylated ghrelin was observed in cells that carry mutations in RAS and $\mathrm{RAF}$, the link between $\mathrm{CAMP}$ and MAPK signaling was next examined in MCF7, MDA-MB-468 and MDA-MB-231 cells in 3D (Figure 2H). Inhibition of MEK activity using U0126 led to a significant reduction in the forskolin-stimulated growth of all cell lines.

\section{Unacylated ghrelin inhibits MAPK and Akt signaling}

Since unacylated ghrelin suppresses CAMP, which we found to stimulate cell growth via MAPK-dependent mechanisms, we next sought to determine whether unacylated ghrelin affected MAPK signaling in 3D cultures, both acutely and chronically. Effects of unacylated ghrelin on ERK activity were examined in real-time using time-lapse confocal microscopy of the FRET-based extracellular signal-regulated kinase activity reporter (EKAR) in MCF7, MDA-MB-468 and MDAMB-231 cells (Figure 3A-B; Figure S3A). Serum stimulated EKAR activity, whereas unacylated ghrelin and the MEK inhibitor, U0126, inhibited this effect. Effects of unacylated ghrelin on MAPK signaling were then examined. Unacylated ghrelin caused a decrease in the phosphorylation of ERK and downstream target, p90RSK (Figure 3B). The effect on p90RSK was sustained for $24 \mathrm{hrs}$ in MCF7 and MDA-MB-468 cells, but this suppression was not observed in MDA-MB-231 cells, at any time point (Figure S3). The levels of MAPK target cMyc, induced by serum, were also suppressed in cells treated with unacylated ghrelin (Figure 3C). No effect on p38 MAPK was observed (Figure 3D). Effects on Akt phosphorylation and activity were then examined by immunoblotting and by quantifying levels of FoxO3 nuclear localization in 3D in real time (Figure $3 \mathrm{E}$ and $3 \mathrm{~F}$; Figure $\mathrm{S} 3 \mathrm{I}-\mathrm{N}$ ). Unacylated ghrelin inhibited the serum-stimulated phosphorylation of Akt (Ser473) and downstream target p70S6K (Thr389) in MCF7 and MDA-MB-468 cells. For MCF7 cells, inhibition of Akt phosphorylation was noticeable at 5 and $15 \mathrm{~min}$, and sustained for $24 \mathrm{~h}$, while effects in MDA-MB-468 cells were discernable at the $24 \mathrm{~h}$ time point only. Effects on Akt activity, measured by examining the degree of serumstimulated FoxO3 nuclear exclusion, were observed in real time, with unacylated ghrelin and PI3K inhibitior (LY294002) causing a significant reduction in FoxO3 nuclear exclusion 
bioRxiv preprint doi: https://doi.org/10.1101/2020.01.22.915744; this version posted January 23, 2020. The copyright holder for this preprint (which was not certified by peer review) is the author/funder, who has granted bioRxiv a license to display the preprint in perpetuity. It is made available under aCC-BY-NC-ND 4.0 International license.

Au et al, Unacylated ghrelin and AZP531 suppress the 3D growth of breast cancers - preprint

A
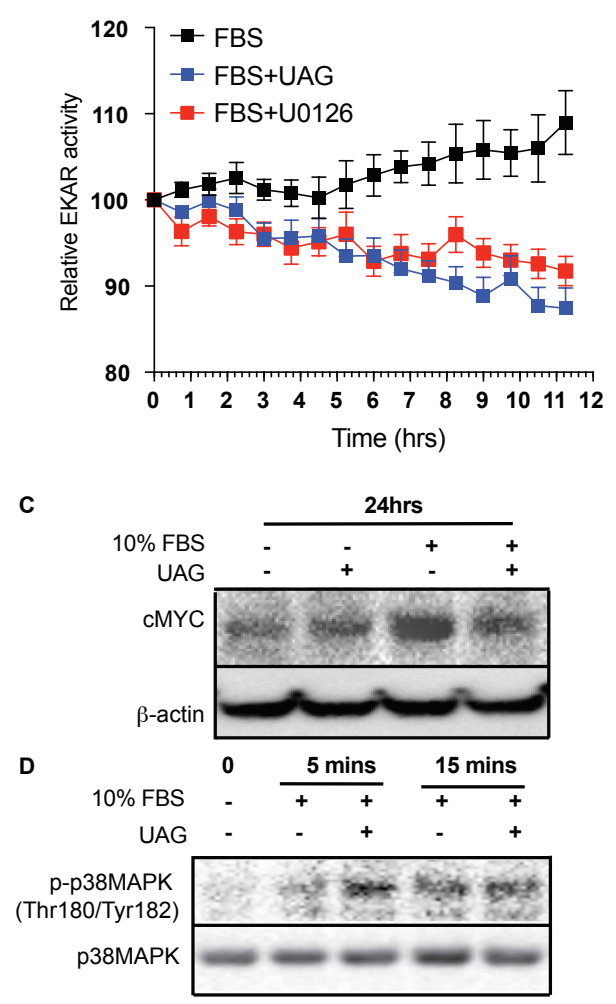
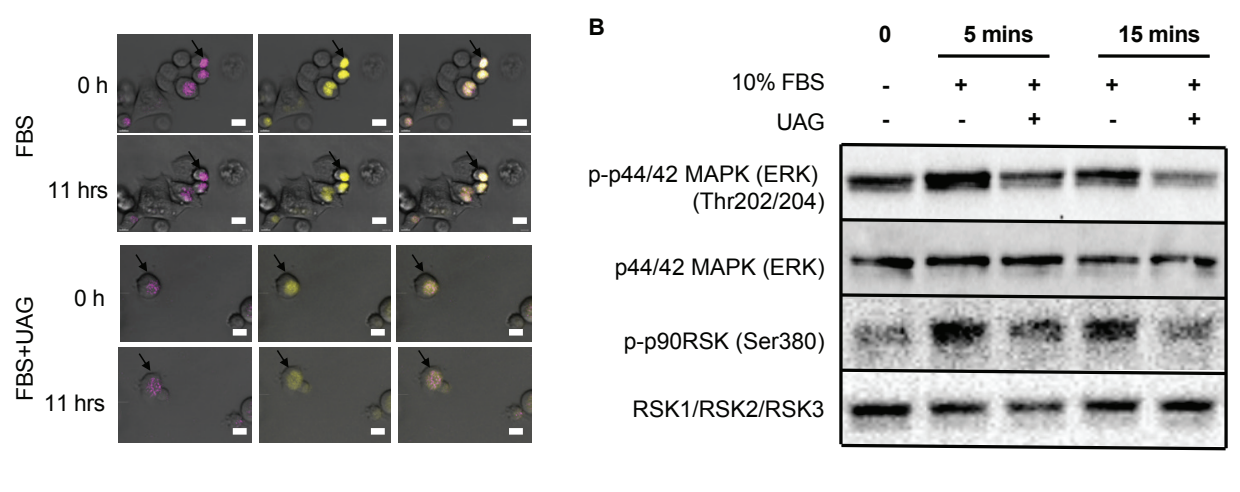

$\mathrm{E}$

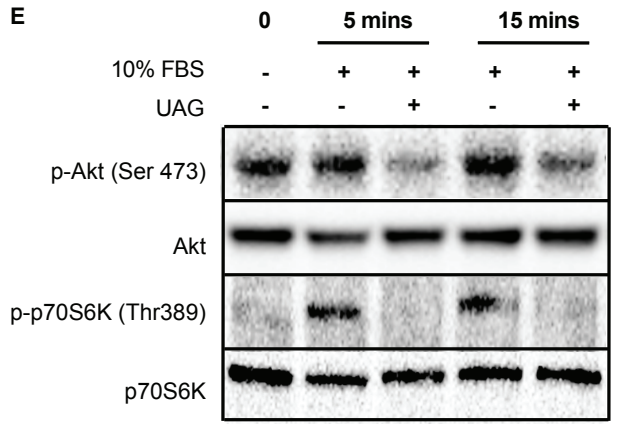

$\mathbf{F}$

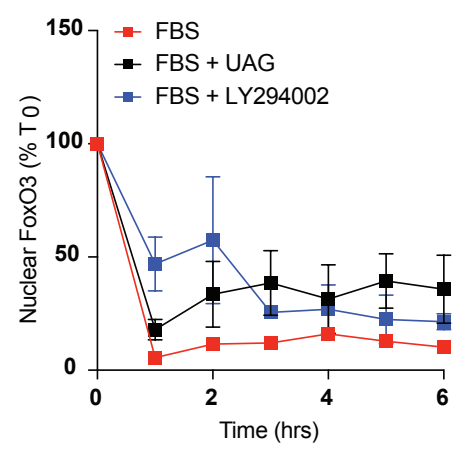

Figure 3. Unacylated ghrelin (UAG) inhibits MAPK and Akt signaling. (A) UAG (100pM) inhibits ERK activity (EYFP FRET) in EKAR-transfected MCF7 cells. Data were normalized to ECFP signal. Scale bar represent 50 $\mu \mathrm{m}$. Western blotting demonstrates that UAG causes a decrease in the (B) phosphorylation of ERK1/2 and downstream MAPK target p90RSK and (C) expression of cMYC in MCF7 cells, (D) while it had no effect on the phosphorylation of p38MAPK. UAG also causes a decrease in (E) the phosphorylation of Akt and its downstream target, p70S6K, as well as (F) FoxO3a nuclear localization FoxO3a-RFP-transfected cells, an effect that is attenuated in cells treated with PI3K inhibitor LY294002. Data represent mean \pm SEM with $n \geq 3$. Experiment repeat at least twice. UAG: unacylated ghrelin; FBS: fetal bovine serum

after $1 \mathrm{~h}$ treatment. No effect of unacylated ghrelin on Akt phosphorylation or activity was observed in MDA-MB-231 cells. These data suggest that unacylated ghrelin inhibits cell proliferation via effects on MAPK and Akt signaling.

\section{Unacylated ghrelin causes cell cycle arrest and apoptosis}

Additional studies were then undertaken to determine whether effects of unacylated ghrelin on cell number were due to stimulation of cell cycle arrest or apoptosis, or both. The effects of unacylated ghrelin on cell proliferation were examined by assessing EdU incorporation in breast cancer cell lines grown in 3D. Estradiol and serum caused a significant increase in EdU incorporation and unacylated ghrelin suppressed DNA synthesis at 10, 100 and $1000 \mathrm{pM}$ (Figure 4A; Figure S4A). The effect of unacylated ghrelin on phases of the cell cycle was assessed in breast cancer cell lines in live cells in 3D using the Premo FUCCl Cell Cycle Sensor, which consists of RFP-tagged cdt1 and GFP-tagged geminin (Figure 4B and 4C; Figure S4B). In G1, geminin is degraded, leaving only the RFP signal. In S, G2 and M phases, cdt1 is degraded and hence, only the GFP signal is detected. During the G1/S transition, cells express both proteins with overlapping fluorescence appearing as yellow. Treatment with unacylated ghrelin was associated with an increase in cells arrested at the G1 phase of the cell cycle in MCF7 and MDA-
MB-468 cells, with no significant effect in MDA-MB-231 cells. Unacylated ghrelin also caused apoptosis in serumstimulated MCF7 and MDA-MB-468 cells, measured in 3D using membrane-impermeant nucleic acid dye ethidium homodimer III and using FACS analysis of Annexin V-stained cells (Figure 4F; Figure S4). Consistently, unacylated ghrelin suppressed the serum-stimulated expression of CDK4 and cyclin D3, important for cell cycle G1 phase progression, and decreased phosphorylation of Rb at Ser795, known to prevent the degration of this cell cycle arrest protein. Treatment with unacylated ghrelin was also associated with a decreased expression of anti-apoptotic protein BCL2, while stimulating the expression of pro-apoptotic factor BAX (Figure 4G-H). This effect was not observed in MDA-MB-231 cells (Figure S4C). These data therefore suggest that unacylated ghrelin decreases cell number by stimulating cells to arrest in G1 and stimulating apoptosis.

\section{Unacylated ghrelin and cyclic analog AZP-531 inhibit tumor} growth in xenograft models and patient-derived tumor cells The effect of unacylated ghrelin on tumor growth in vivo was examined in orthotopic xenograft and allograft mouse models. In MCF7 and ZR75 xenografts, daily s.c. injection of $50 \mu \mathrm{g} / \mathrm{kg}$ and $100 \mu \mathrm{g} / \mathrm{kg}$ unacylated ghrelin led to a significant reduction in tumor volume (Figure 5A and 5B). Effects were 
bioRxiv preprint doi: https://doi.org/10.1101/2020.01.22.915744; this version posted January 23, 2020. The copyright holder for this preprint (which was not certified by peer review) is the author/funder, who has granted bioRxiv a license to display the preprint in perpetuity. It is made available under aCC-BY-NC-ND 4.0 International license.
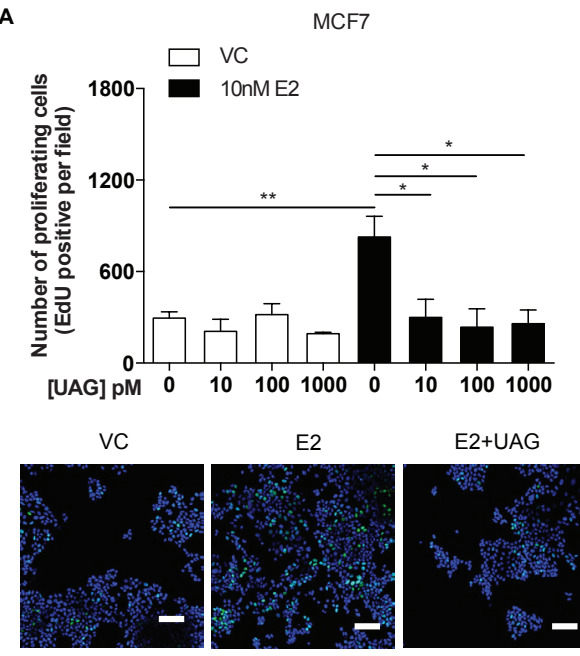

D
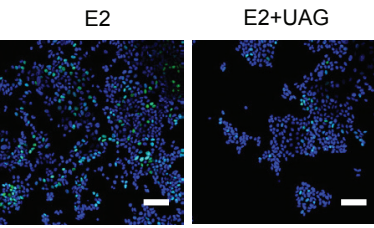

MCF7

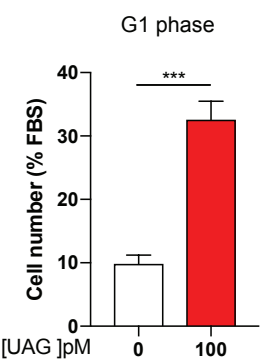

S/G2/M phase
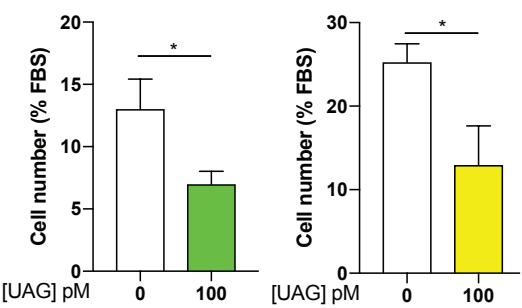

FBS
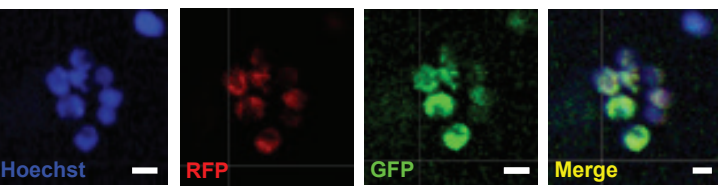

FBS+UAG
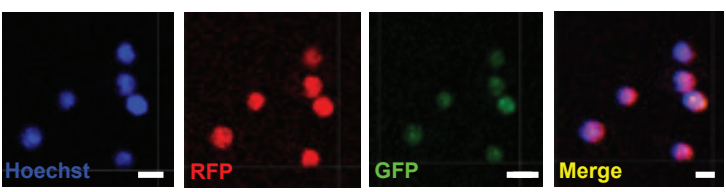

$\mathbf{F}$

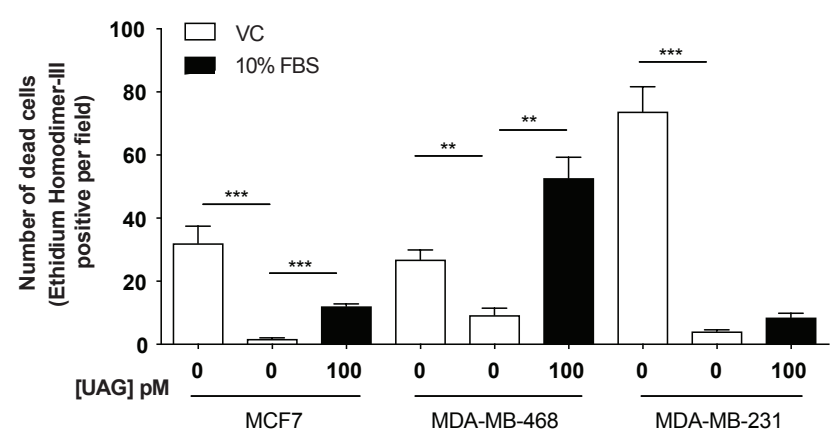

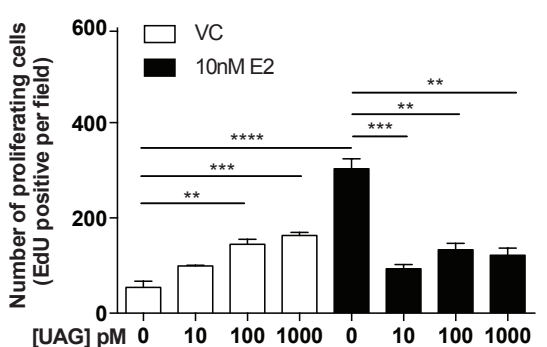

$E 2+U A G$

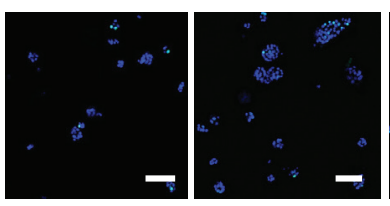

E

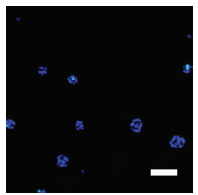

G1 phase

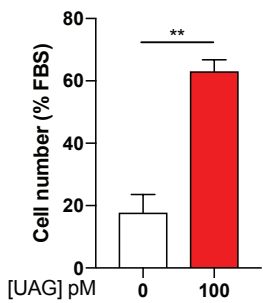

FBS

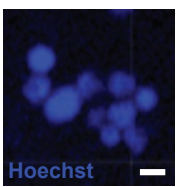

FBS+UAG
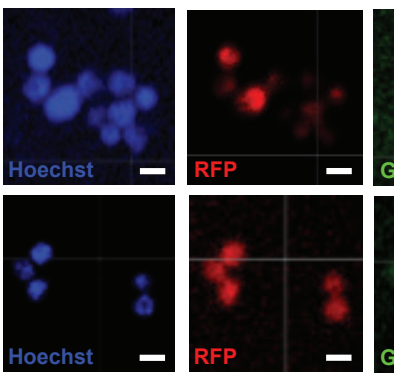

G

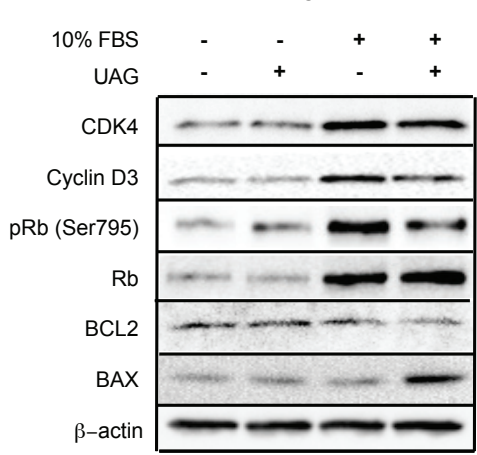

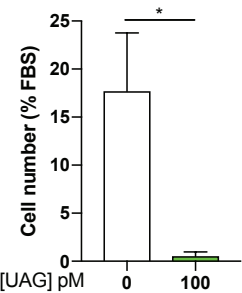
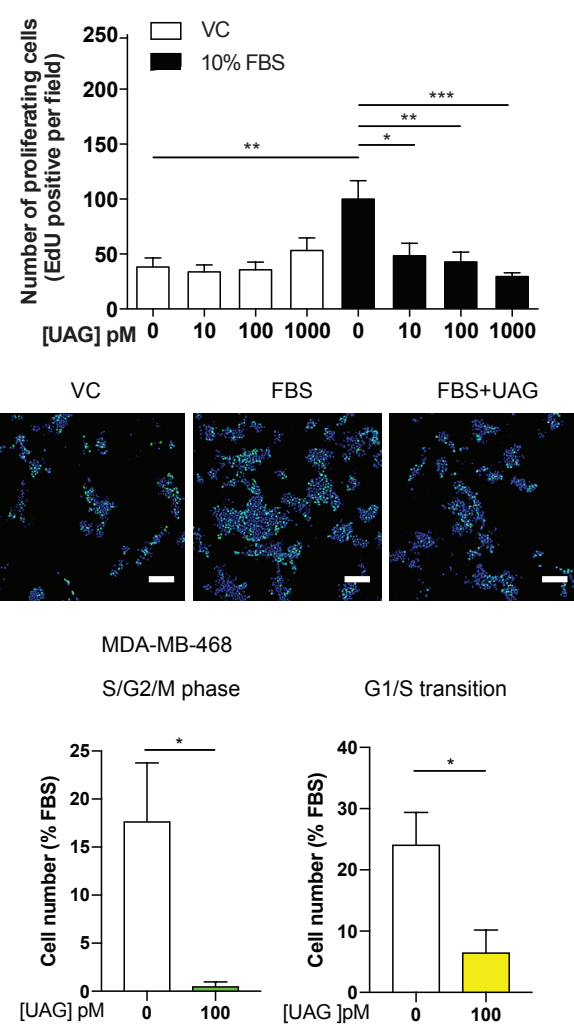

MDA-MB-468

S/G2/M phase

G1/S transition
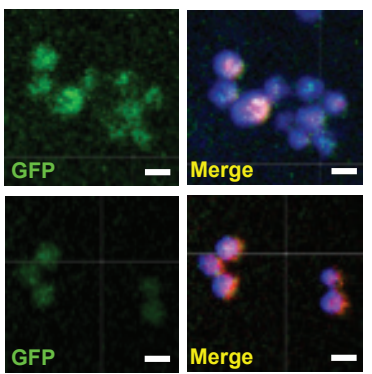

H
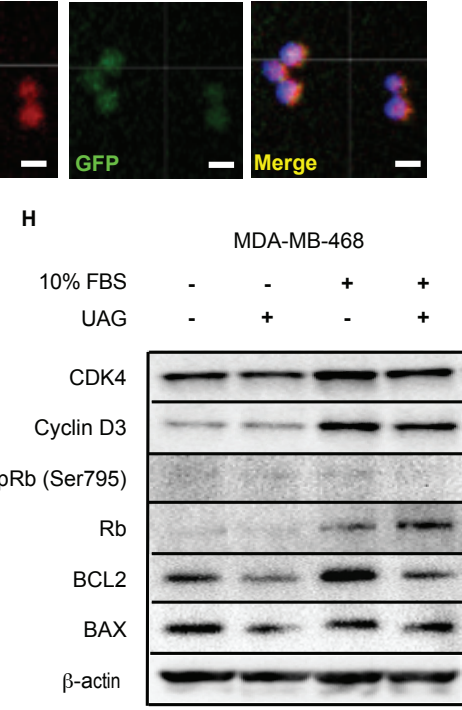

Figure 4. Unacylated ghrelin (UAG) causes cell cycle arrest and apoptosis. UAG significantly inhibits the proliferation of (A) MCF7, (B) ZR75 and (C) MDAMB-468 in the presence of estradiol (10nM) or serum. Representative images showing EdU incorporation (green). Hoechst nuclear stain; blue. Scale bar represent $100 \mu \mathrm{m}$. Effects are mediated via induction of G1-phase cell cycle arrest (RFP+) and a reduction in the number of cells in S/G2/M-phase (GFP+) and G1/S transition (YFP+) in (D) MCF7 and (E) MDA-MB-468 cells. (Hoechst nuclear stain; blue). Scale bar represents 100 $\mu m$. (F) UAG stimulates cell death in MCF7 and MDA-MB-468 cells, but not MDA-MB-231 cells. Western blot results demonstrating that UAG inhibits CDK4/cyclin D3, pRB (Ser 795) and BCL2, and stimulates BAX in (G) MCF7 and (H) MDA-MB-468 cells. Data represent mean \pm SEM with $n \geq 3$. Experiments were repeated at least twice. UAG: unacylated ghrelin; VC: vehicle control; FBS: fetal bovine serum; E2: estradiol. 
bioRxiv preprint doi: https://doi.org/10.1101/2020.01.22.915744; this version posted January 23, 2020. The copyright holder for this preprint (which was not certified by peer review) is the author/funder, who has granted bioRxiv a license to display the preprint in perpetuity. It is made available under aCC-BY-NC-ND 4.0 International license.

Au et al, Unacylated ghrelin and AZP531 suppress the 3D growth of breast cancers - preprint

then assessed in a syngeneic model of mammary cancer. In the J110 allograft model, unacylated ghrelin caused a significant reduction in tumor growth at $100 \mu \mathrm{g} / \mathrm{kg}$ and 200 $\mu \mathrm{g} / \mathrm{kg}$ (Figure $5 \mathrm{C}$ ). Effects of unacylated ghrelin to suppress the growth of $\mathrm{J} 110$ cells was not dependent on the host immune context, as similar results were obtained when cells were xenografted in Balb/c nude immunocompromised mice (Figure S5D). The degree of apoptosis in tumors at endpoint was quantified by counting the percentage of cells with pyknotic nuclei in tumors. Unacylated ghrelin significantly increased the number of apoptotic cells in MCF7, ZR75 and J110 xenografts/allografts (Figure 5D and 5F). The effects of unacylated ghrelin were also examined in patient-derived breast cancer cells. Unacylated ghrelin at 100pM caused a significant reduction in the serum-induced growth of ER+ breast cancer cells and the basal-like subset of TNBC cells, but not mesenchymal TNBCs (Figure 5G; Figure S5E; Table 1). BRAF and KRAS mutation status has not been characterized
A
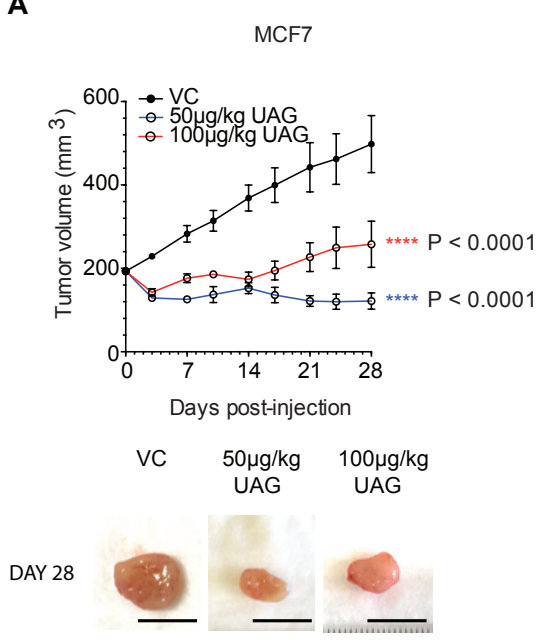

D
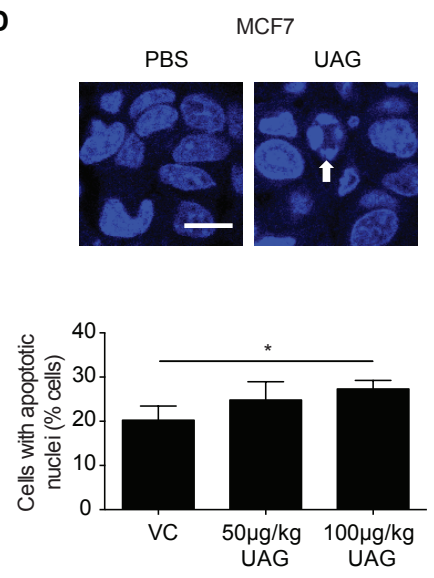

G

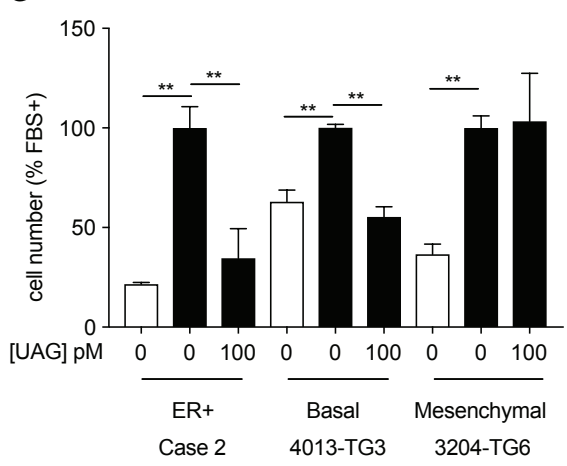

B
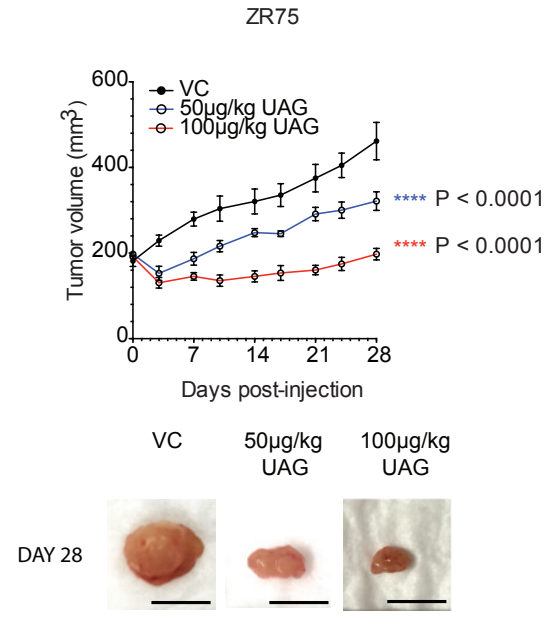

E
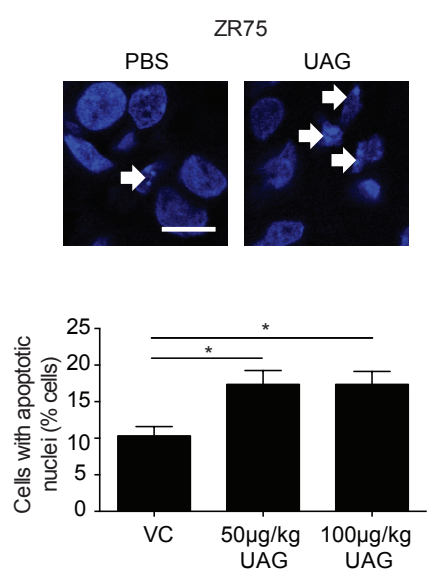

C
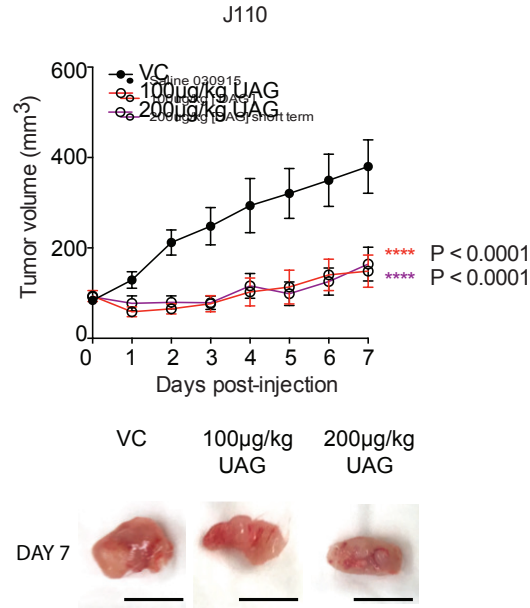

$\mathbf{F}$
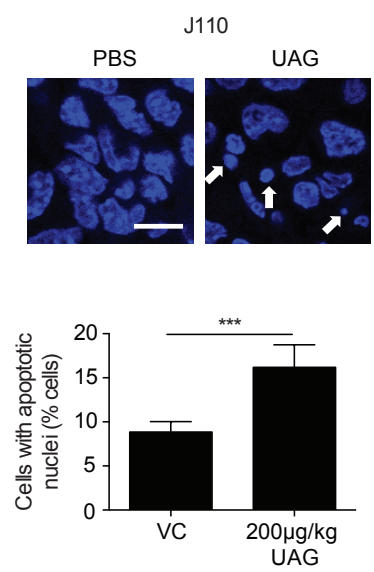

H

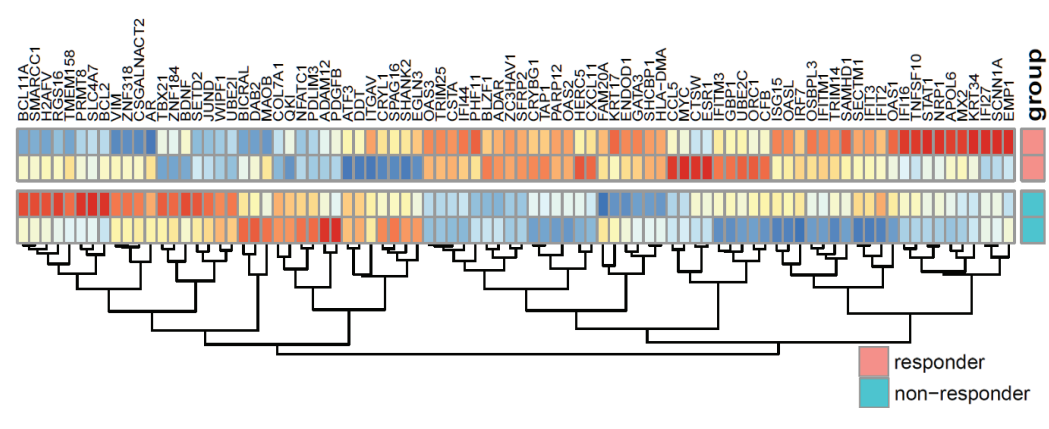

Figure 5. Unacylated ghrelin (UAG) inhibits tumor growth in xenograft models and patient-derived tumor cells. Tumor volume in response to treatment with $50 \mu \mathrm{g} / \mathrm{kg}$ (blue), $100 \mu \mathrm{g} / \mathrm{kg}$ (red) or 200 $\mu \mathrm{g} / \mathrm{kg}$ (purple) UAG in mice xenografted with (A) MCF7 (n=6/group), (B) ZR75 (n=5/group), allografted with (C) J110 (n=5/ group) cells. Representative tumor (below) with scale bar representing $10 \mathrm{~mm}$. UAG significantly increases the number of cells with apoptotic nuclei in (D) MCF7, (E) ZR75 and (F) J110 xenografts. (G) UAG (100pM) significantly inhibits the growth of patient-derived ER+ breast cancer cells and basal-like (BL) TNBC cells, but not mesenchymal (M) TNBC cells. (H) Heatmap representing baseline differential expression of MAPK-target genes in responsive vs. non-responsive patient-derived cells. Data represent mean \pm SEM with $n \geq 3$. UAG: unacylated ghrelin; VC: vehicle control; FBS: fetal bovine serum. 
bioRxiv preprint doi: https://doi.org/10.1101/2020.01.22.915744; this version posted January 23, 2020. The copyright holder for this preprint (which was not certified by peer review) is the author/funder, who has granted bioRxiv a license to display the preprint in perpetuity. It is made available under aCC-BY-NC-ND 4.0 International license.

Au et al, Unacylated ghrelin and AZP531 suppress the 3D growth of breast cancers - preprint

A

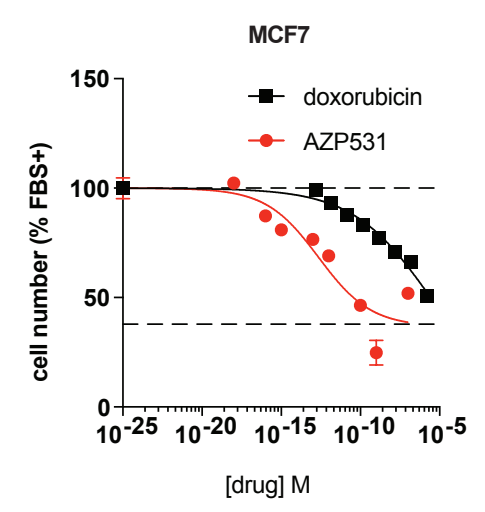

B

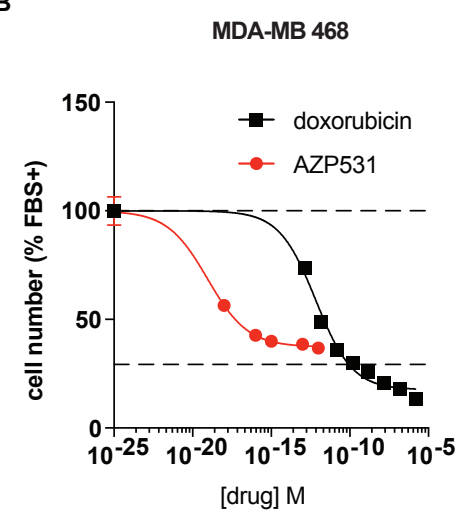

C

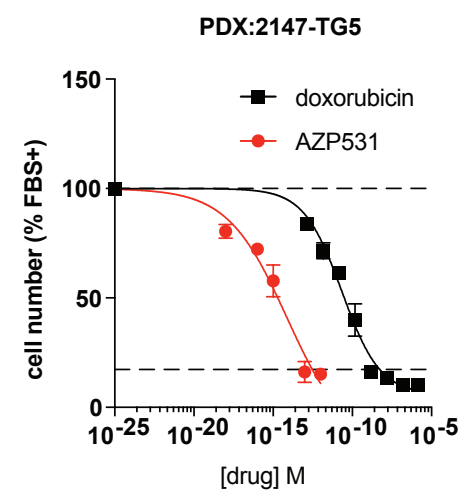

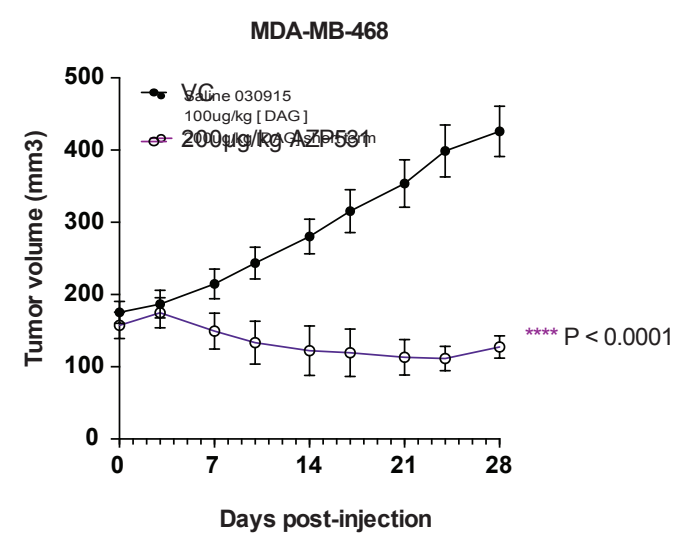
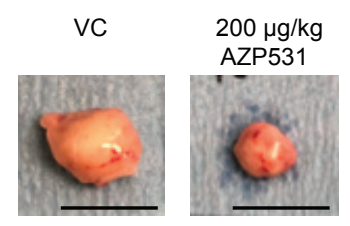

E

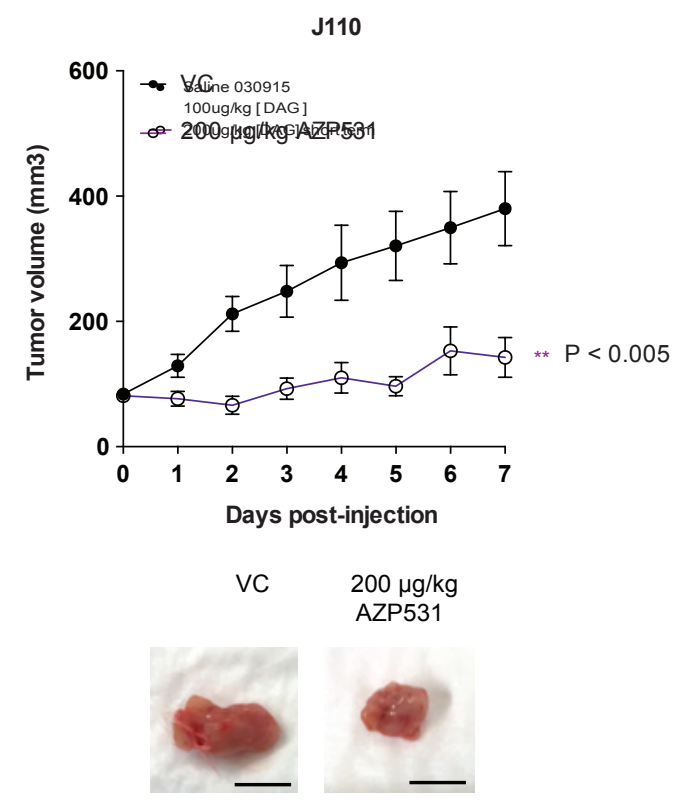

Figure 6. Cyclic unacylated ghrelin analog AZP531 inhibits the growth of breast cancer cells in vitro and in vivo. AZP531 causes the dose-dependent inhibition of (A) MCF7 and (B) MDA-MB-468 and (C) patientderived TNBC breast cancer cell growth in $3 \mathrm{D}$, compared with chemotherapeutic agent doxorubicin. Data represent mean \pm SEM with $\mathrm{n} \geq 3$. Experiments were repeated at least twice. Tumor volume in response to treatment with $200 \mu \mathrm{g} / \mathrm{kg}$ AZP531 (purple) in mice xenografted with (D) MDA-MB-468 ( $n \geq 8$ /group) or allografted with (E) J110 ( $n=5 /$ group) cells. Representative images (below) with scale bars representing $10 \mathrm{~mm}$. in these patient samples. Interestingly, Ingenuity Pathway Analysis (causal analysis) of gene expression indicated that MAPK-target genes were differentially expressed between responsive and non-responsive TNBC patient-derived samples, such that non-responsive cells had gene expression consistent with activation of MAPK signaling.

\section{Unacylated ghrelin analog, AZP531, inhibits breast cancer cell growth in vitro, ex vivo and in vivo}

AZP531 is a cyclic analog of unacylated ghrelin comprised of amino acids Ser6-GIn12 of the unacylated ghrelin peptide. It is a well-tolerated drug that is more stable than unacylated ghrelin. In order to determine whether this clinically available treatment has similar effects to parent peptide unacylated ghrelin, the effect of AZP531 on breast cancer cell growth was examined in MCF7, MDA-MB-468, and patient-derived TNBC cells, and compared to chemotherapeutic doxorubicin (Figure 6 A-C). AZP531 caused the dose-dependent inhibition of the serum-stimulated growth of cells with greater potency than doxorubicin, but unlike doxorubicin, did not reduce cell number beyond that which was stimulated by serum. Importantly, AZP531 caused the suppression of cell growth in preclinical models, including TNBC MDA-MB-468 xenografts and ER+ J110 allografts, at $200 \mu \mathrm{g} / \mathrm{kg}$ (Figure 6D and $6 \mathrm{E}$, respectively). These data suggest that AZP531 may be efficacious at suppressing the growth of ER+ tumors and TNBC in women.

\section{DISCUSSION}

Our work provides evidence that unacylated ghrelin is a 
potent inhibitor of breast cancer cell growth and provides mechanistic insights not previously described for this peptide hormone. Little is known of the relationship between ghrelin, unacylated ghrelin and effects on breast cancer risk and progression. One report recently demonstrated that tumor ghrelin expression is associated with a favorable outcome in invasive breast cancer (Gronberg et al., 2012). More specifically, ghrelin immunoreactivity is significantly correlated with low histological grade, estrogen receptor positivity, small tumor size, low proliferation, as well as better recurrence-free and breast cancer-specific survival. The polyclonal antibody used was generated against fulllength human ghrelin and hence potentially cross-reacts with unacylated ghrelin. In the present manuscript, both ghrelin and unacylated ghrelin were found to cause potent inhibition of breast cancer cell growth at picomolar doses when cells are grown in a biologically relevant extracellular matrix (ECM). Previous in vitro work examining the effects of ghrelin and unacylated ghrelin in breast cancer saw very little effects at sub-micromolar doses (Cassoni et al., 2001). This is likely due to prior studies having been undertaken using traditional culture methods where cells were grown in 2D on plastic and highlights important mechanistic differences when cells are cultured in 3D surrounded by an ECM. The importance of modeling breast and other cancers using 3D systems has been emphasized in a number of recent studies. Importantly, differences in signaling pathway activation are noted and 3D systems are hypothesized to allow for better prediction of in vivo effects (Gangadhara et al., 2016; Weigelt et al., 2014). Our findings, and that of others, suggest that tumor cell culture context affects response to therapy and that many translational failures may have resulted from the inappropriate model systems used to date. It also suggests that others may have overlooked many effective therapies due to a lack of response in 2D cultures.

The cognate ghrelin receptor, GHSR1a, does not bind to unacylated ghrelin and is undetectable in most breast cancer cell lines (Callaghan and Furness, 2014; Cassoni et al., 2001), suggesting that both ghrelin and unacylated ghrelin are acting at an alternate ghrelin receptor. In order to start dissecting the mechanism of action of unacylated ghrelin, cues were taken from our previous studies in adipose stromal cells where treatment results in inhibition of cAMP (Docanto et al., 2014). Results in the present study are consistent with these previous findings, and further demonstrate that unacylated ghrelin treatment is associated with activation of Gai. The evidence for the importance of cAMP in breast cancer biology has been inconsistent. A number of studies have demonstrated pro-proliferative effects (Aronica et al., 1994; Kung et al., 1983), while others show that cAMP and activation of PKA inhibit cell growth (Chen et al., 1998; ChoChung et al., 1981; Fontana et al., 1987). Effects appear to be cell and context dependent. Directionality also seems more robust for studies performed using clinical samples. For example, cAMP levels have been shown to be 15 times higher in human breast cancer compared to normal breast tissue (Minton et al., 1974) and the overall ability to hydrolyze cyclic nucleotides has been shown to be decreased in faster growing and more invasive mammary cancers (Fajardo et al., 2014). PKA regulatory subunit expression and catalytic activity have also been shown to be increased in malignant compared to normal breast tissue (Gordge et al., 1996), suggesting that CAMP and PKA promote breast cancer growth. Here, we demonstrate that inhibition of cAMP formation or action mimics the effects of unacylated ghrelin to inhibit breast cancer cell growth in 3D. Our findings demonstrating that cells are insensitive to the effects of unacylated ghrelin in the presence of a BRAF or KRAS mutation also suggests that unacylated ghrelin acts upstream of these signaling proteins. Consistently, the growth-stimulatory effects of cAMP are dependent on MAPK signaling, known to be tightly regulated by BRAF/KRAS signaling.

Effects of unacylated ghrelin to inhibit cell cycle progression and stimulate apoptosis are also consistent with inhibition of MAPK and Akt signaling. Growth factor signaling has previously been shown to cause the accumulation of myc and cyclin D proteins, key drivers of the G1-to-S phase transition, as well as lead to the activation of CDK4 and the hyperphosphorylation of Rb (Hipfner and Cohen, 2004; O'Leary et al., 2016). Because cell number is not suppressed beyond what is stimulated by mitogens, effects are likely dependent on signaling downstream of the growth stimulus. The activity of unacylated ghrelin and unacylated ghrelin analogs to suppress MAPK and Akt signaling, myc, cyclin D3 and CDK4 expression, could therefore be leveraged in a therapeutic setting.

The unacylated ghrelin analog, AZP531, was shown to be well tolerated in a phase I clinical trial performed in overweight and obese subjects with type II diabetes, and significant improvements in glucose variables were observed (Allas et al., 2016). A phase II study was also undertaken in individuals with Prader-Willi Syndrome, where daily subcutaneous injections of AZP531 for 14 days caused a significant improvement in scores on the hyperphagia questionnaire, and a reduction in waist circumference, fat mass and post-prandial glucose levels (Allas et al., 2018). We have demonstrated efficacy of AZP531 in reducing the growth of breast cancer cell lines and patient-derived cancer cells, consistent with effects of unacylated ghrelin. Based on the data obtained using a panel of breast cancer cell lines and effects seen in patient-derived tumor cells, we also identify the subset of breast cancers that will be resistant to treatment, i.e. TNBCs with KRAS or BRAF mutations, or TNBCs with high MAPK activity. KRAS has been shown to maintain mesenchymal features of TNBCs (Kim et al., 2015). As less than $1 \%$ of breast tumors carry these mutations (Tilch et al., 2014), it is likely that unacylated ghrelin and AZP531 will be effective in the majority of breast cancers. Since UAG has also been shown to prevent chemotherapyinduced muscle cell death (Nonaka et al., 2017), there is potential to combine unacylated ghrelin or AZP531 with chemotherapy, while also reducing cardiotoxicity.

\section{Acknowledgements}

We thank R. Clarke, J. Yun, B. Vogelstein, M. Brown for providing cell lines. We are grateful to D. Gough (BRAF transient transfections), J. Albeck (EKAR and AKT activity assay) and M. Foronda (CRISPR) for provision of reagents 
and valuable experimental advice. We acknowledge S. Yomtoubian for providing information relating to TNBC subtype and T. Pham for assistance with data analysis. We are indebted J. Cain, S.N. Jayasekara and M. Docanto for assistance with in vivo work; the Monash Micro Imaging Facility, Monash Animal Research Platform, MHTP Medical Genomics Facility, MHTP Flow Cytometry Facility and Research Animal Resource Center at Weill Cornell Medicine for valuable discussions and comments. Financial support: This work was supported by a grant from the National Breast Cancer Foundation (NC-14-011 to KAB), and by the Victorian Government Operational Infrastructure Support Program. CCA was supported by an Endocrine Society of Australia Research Higher Degree Scholarship. KAB was supported by an NHMRC (Australia) Career Development Award GNT1007714, the Endocrine Society of Australia Ken Wynne Memorial Postdoctoral Research Award, and by the Mavis Robertson Fellowship from the National Breast Cancer Foundation (NBCF; ECF-16-004). KB was supported by an NBCF Early Career Fellowship.

\section{Author Contributions}

C.C.A., S.O., H.L., B.C., C.G. performed and analyzed in vitro experiments. C.C.A., K.B., K.Y.S., Y.W., X.Y.H. performed and analyzed in vivo experiments. J.A.S. provided expertise and reagents (collagen) related to 3D culture techniques. G.G.I., V.M. and E.A. provided breast cancer biospecimens. L.E.D. designed gRNA and provided expertise related to CRISPR studies. P.Z. and D.B. analyzed microarray datasets. J.B.F. and K.A.B. supervised and provided valuable insights for the study. C.C.A. and K.A.B. conceived the experiments, analyzed results, managed the project, and wrote the manuscript.

\section{Conflict of Interest Statement}

Cornell University has filed a patent application on the work that is described in this paper. The authors declare no other competing interests.

\section{METHODS}

Human breast cancer tissues and preclinical patient derived xenograft models

Patient-derived breast tumors (PDX (Zhang et al., 2013)) were obtained from Dr. Giorgio Inghirami and estrogen receptor positive (ER+) breast tumors were obtained from Dr. Eleni Andreopoulou at Weill Cornell Medicine under IRB-approved protocols (WCM 1410015560 and 1603017108). All patients provided written informed consent. Cells were isolated and maintained in DMEM, supplemented with $10 \%$ fetal calf serum (FCS), $100 \mathrm{U} / \mathrm{ml}$ penicillin/ streptomycin and $1 \%$ sodium pyruvate (ThermoFisher Scientific). Cells were grown at $37 \mathrm{oC}$ in a humidified atmosphere with 5\% CO2. See Method Details for cell growth and proliferation work specific procedures.

\section{Human breast cancer cells}

Human breast cancer cell lines, MCF7, T47D, ZR75, MDA-MB-231, MDAMB-468, SKBR3, Hs578T and HEK293T, DU4475 and MDA-MB-157 were purchased from ATCC, USA. Human 4-OH tamoxifen resistant breast cancer cells (LCC2) were obtained from Prof. Robert Clarke. RKO, RKO-T29, RKO-A19, HCT116, HCT116-HWT, HCT116-HMUT were obtained from Dr. Jihye Yun and Dr. Bert Vogelstein and culture methods were performed as described previously (Yun et al.,2009). MCF7, MDA-MB-231, MDA-MB-468, MDA-MB-157, Hs578T, HEK293T were grown in DMEM (Invitrogen), supplemented with $10 \%$ fetal calf serum (FCS) (Invitrogen), $100 \mathrm{U} / \mathrm{ml}$ penicillin/streptomycin and 1\% sodium pyruvate. ZR75, T47D, SKBR3 and DU4475 were grown in RPMI, supplemented with $10 \%$ FCS, $100 \mathrm{U} / \mathrm{ml}$ penicillin/streptomycin and $2 \mathrm{mM}$ L-Glutamine (ThermoFisher Scientific). LCC2 were grown in phenol red-free DMEM, supplemented with $10 \%$ charcoal stripped serum (CCS; ThermoFisher Scientific), $100 \mathrm{U} / \mathrm{ml}$ penicillin/ streptomycin and $1 \%$ sodium pyruvate. All cell lines were grown at $37 \mathrm{oC}$ with 5\% CO2 in a humidified environment. Mycoplasma detection of all cell lines were tested and negative results were observed.

\section{Animal experimental model}

All animal experiments were performed in Monash Animal Research Platform at Hudson Institute for Medical Research and Research Animal Resource Center at Weill Cornell Medicine. Experimental procedures were in accordance with guidelines for Animal Care and Use, approved by Monash University Animal Ethics Committee (MMCA2014/20) and Weill Cornell Medicine IACUC Protocol (REQ00016929). Athymic Balb/c nude, FVB/N (Animal Resources Centre, Australia) and NSG (NOD Scid gamma; NOD.CgPrkdcscidll2 $\mathrm{rgtm} 1 \mathrm{wj} / \mathrm{Sz}$ ) mice (The Jackson laboratory and Monash
Breeding Colony platform) were used for this study. All mouse procedures were performed with 6-8 weeks old female mice and treatments administered via subcutaneous injection. See Method Details for in vivo work specific procedures.

\section{Cell growth and proliferation assays}

3D culture of a panel of breast cancer and colon cancer cells were seeded at a density of 3,000 cells per well in media containing 30\% growth-factorreduced matrigel or $5 \mathrm{mg} / \mathrm{ml}$ Collagen (obtained from Dr. Jason Spector) in optical-bottom 96-well plates. Patient-derived breast tumors were first dissociated into single cell suspensions and seeded at a density of 32,000 cells per well in media containing $30 \%$ matrigel. Cells were serum-starved overnight and cultured under different experimental conditions (10-1000 pM unacylated ghrelin, $100 \mathrm{pM}$ ghrelin, $1.5 \times 10-13-1.5 \times 10-6 \mathrm{M}$ doxorubicin, $1 \times 10-18-1 \times 10-7$ M AZP531, 20-200 ng/ml pertussis toxin, $10 \mu \mathrm{M} \cup 0126$ (MEK inhibitor), $10 \mu \mathrm{M}$ LY294002 (PI3K inhibitor), 0.05-5 $\mu \mathrm{M}$ MK2206 (a highly selective inhibitor of pan-Akt), 0.1-10 $\mu \mathrm{M}$ BKM120 (a pan-class I PI3K inhibitor), 60 nM KT5720, $1.4 \mu \mathrm{M}$ SQ22536, $15 \mu \mathrm{M}$ cAMPs-RP, $10 \mathrm{nM}$ melatonin and the combination of doxorubicin/unacylated ghrelin or doxorubicin/AZP531, with or without $10 \mathrm{nM}$ estradiol or $10 \%$ serum or $1 \mu \mathrm{M}$ forskolin) and medium was replaced every 2 days. At the end of the experimental time point, cells were fixed in $100 \%$ methanol. The total number of cells, or the number of dead or proliferating cells was assessed using Hoechst, EarlyTox Dead Assay Kit (Molecular Devices), or Click-IT EdU Kit (ThermoFisher Scientific), respectively, and analyzed according to the manufacturer's protocols. Cells were then imaged with $>95 \%$ well coverage (magnification of 10x with $3 \times 3$ tiled images) per field using confocal microscopy. The number of nuclei/ Ethidium Homodimer-III+/EdU+ cells were counted using Imaris software (Bitplane).

\section{Microscope image acquisition}

Imaging of wells with greater than 95\% coverage was acquired using a 10X/ NA 0.8 objective by tiling $3 \times 3$ using confocal microscopy (Zeiss LSM880) with Axiocam. The fixed cells were imaged at room temperature, while the live cell images were acquired at $37 \mathrm{oC}$ placed inside a temperature and $\mathrm{CO} 2$ regulated chamber. The number of nuclei/ Ethidium Homodimer-III+/EdU+ cells were measured using the Zen (Zeiss Enhanced Navigation) and counted using the Imaris software (Bitplane).

\section{Binding assays}

Cy3-tagged UAG (Pepmic Co,LtD) binding assays were performed in 3D cultures of breast cancer cells. MCF7, MDA-MB-469 and MDA-MB231 cells were seeded at a density of 3,000 cells per well in Matrigel in optical-bottom 96-well plates. Cells were serum-starved overnight. Hoechst nuclear stain was added prior to the live cell imaging. $1 \mu \mathrm{M}$ Cy3-tagged UAG with $10 \%$ serum was then added and time-lapse confocal imaging was performed to examine the localization of peptide binding.

\section{BRAF Transient transfections}

Two million cells were harvested and transfected with or without $1.5 \mu \mathrm{g}$ of BRAFV600E plasmid (obtained from Dr. Dan Gough) using AMAXA Nucleofector (Lonza), according to supplier's instructions. Transfected cells were then cultured according to above sections (cell growth and proliferation assay). After 5 days, cell number per field was assessed using Hoechst nuclear stain, confocal microscopy and Image J.

\section{GNAI CRISPR KO generation}

The lentiviral construct, lentiCRISPRv2 (containing hSpCas9 and the chimeric guide RNA cassettes; Addgene), was digested using BsmBI. Prior to ligation, each pair of oligos $(100 \mu \mathrm{M})$ were annealed. The oligos (GNAI sequence guide strands) designed were based on the target site sequence (20 bp) and were flanked on the $3^{\prime}$ end by a 3 bp NGG PAM sequence. The gel-purified, $\mathrm{BsmBI}$ digested plasmid was ligated to the diluted (1:200) annealed oligo. The ligation product was transformed into competent Escherichia coli Stbl3TM cells. Ampicillin resistance colonies were selected for miniprep/maxiprep (Promega). For virus production, HEK293T cells were plated in a $10 \mathrm{~cm}$ dish and transfected 24 hours later ( $80 \%$ confluence) with a prepared mix in DMEM media (no supplements) containing $5 \mu \mathrm{g}$ of empty vector or gRNA plasmid of GNAI1, GNAI2 or GNAI3, 2.5 $\mu$ g of psPAX2, $1.25 \mu \mathrm{g}$ of VSV.G, and $15 \mu \mathrm{l}$ of polyethylenimine (PEl; $1 \mu \mathrm{g} / \mathrm{ml}$ ). 24hrs following transfection, media was replaced and supernatants (GNAI1, GNAI2 or GNAI3) were harvested and collected every 24 hrs up to 72 hrs post transfection. To generate CRISPR/Cas9 sgRNA stable breast cancer cell lines, breast cancer cells were 
plated in a 6-well plate. $24 \mathrm{hrs}$ following plating, cells were transfected with CRISPR/Cas9 sgRNA lentiviral vector and $8 \mu \mathrm{g} / \mathrm{ml}$ of polybrene. $24 \mathrm{hrs}$ after transfection, media was replaced. Cells were then selected in puromycin $(2$ $\mu \mathrm{g} / \mathrm{ml}$ ) for 5 days. CRISPR/Cas9 sgRNA stable breast cancer cell lines were then transduced with viral supernatants (GNAI1, GNAI2 or GNAI3 virus) in the presence of polybrene $(8 \mu \mathrm{g} / \mathrm{ml})$. $24 \mathrm{hrs}$ after transduction cells were selected in Blasticidin S $(2 \mu \mathrm{g} / \mathrm{ml})$ for 5 days. Selected cells were used to perform cell growth assays.

\section{ERK and Akt activity assays}

ERK activity assay: The EKAR FRET-based system was used to monitor ERK activity. Briefly, breast cancer cells were co-transfected with pPBJ-puroFRET3-EKAR-nls and the pCMV-hyPBase transposase vector (obtained from Dr. John Albeck), and stably transfected cells selected using FACS for EYFP and ECFP-positive cells. Cells were then cultured in 3D and serum-starved overnight. Prior live cell time-lapse confocal imaging, medium was replaced with $100 \mathrm{pM}$ unacylated ghrelin and $10 \%$ serum. Images were acquired following FRET and analyzed using Imaris software. Data normalized to ECFP signal.

\section{AKT activity assay}

pMSCV-puro-Foxo3a-H212R-N400-mCherry (obtained from Dr. John Albeck) was transfected into breast cancer cells using Amaxa Nucleofector. After 3 days of puromycin $(2 \mu \mathrm{g} / \mathrm{ml})$ selection, transfected cells were cultured in 3D. Cells were serum-starved overnight. Prior to live cell imaging, medium was replaced with $100 \mathrm{pM}$ unacylated ghrelin and $10 \%$ serum. Time-lapse imaging was performed to examine mCherry-tagged FoxO3 localization. Data were analyzed using Hoechst nuclear stain to mask nuclei using Imaris software.

\section{cAMP assay}

The Lance Ultra cAMP kit (Perkin Elmer) was used to measure the effect of unacylated ghrelin on CAMP production. All kit components were prepared according to manufacturer's specifications. Briefly, MCF7 (475 cells/well) were incubated at room temperature for $60 \mathrm{~min}$ with unacylated ghrelin (10$1000 \mathrm{pM})$, in the absence or presence of forskolin $(0.5 \mu \mathrm{M})$. The Eu-cAMP tracer and Ulight-anti cAMP reagents were then added for 1 hour at room temperature. The plate was then read using the Envision TRF capable reader (Perkin Elmer) and fluorescence was measured with excitation wavelengths of 340 or $340 \mathrm{~nm}$ and emission of $665 \mathrm{~nm}$ according to the manufacturer's instructions.

\section{Intracellular calcium release assay}

Intracellular Ca2+ levels were measured in MCF7, ZR75 and J110 cells by fluorescence using the Flexstation (Molecular Devices, Sunnyvale, CA, USA) as previously described (Callaghan et al., 2012). Briefly, cells were plated, allowed to reach 50-70\% confluency, and loaded with $2 \mu \mathrm{M}$ fura 2-AM for $1 \mathrm{~h}$ in the presence of $2.5 \mathrm{mM}$ probenecid and $0.01 \%$ pluronic $\mathrm{F}-127$ at $37 \mathrm{oC}$. Cells were then washed twice with assay buffer, and changes in fluorescence in response to drug addition were measured over $100 \mathrm{~s}$ using excitation wavelengths of 340 and $380 \mathrm{~nm}$ and emission of $520 \mathrm{~nm}$.

\section{Gai activation assay}

Gai activation assay (NewEast Biosciences) was performed on MCF7 cells according to the manufacturer's protocol. Briefly, cell lysates from 3D cell culture were incubated with an anti-active Gai antibody (1:1000). The precipitated active Gai was immunoblotted with an anti-Gai antibody (1:1000). Bound antibodies were revealed with HRP conjugated secondary antibodies (1:2000) using SuperSignal West pico chemiluminescent solution (Pierce, Rockford, IL). Protein amount was normalized to $\alpha$-tubulin $(1: 10,000)$. Membranes were scanned and the densitometric analysis of the bands was performed using the ChemiDoc MP imaging system (BioRad).

\section{Western blot Analysis}

Western blotting was performed as described previously (Brown et al., 2009). Briefly, cells isolated from or $5 \mathrm{mg} / \mathrm{ml}$ Collagen (obtained from Dr. Jason Spector) were lysed in RIPA lysis buffer (Sigma-Aldrich) supplemented with 100x Protease/Phosphatase inhibitor cocktail (Cell Signaling Technology Inc). Cell extracts ( $20 \mu \mathrm{g}$ per lane) were separated by NuPAGETM $4-12 \%$ BisTris protein gels (ThermoFisher Scientific) and transferred to nitrocellulose membranes. Antibodies details are provided in the key resources table. Bound antibodies were revealed with HRP conjugated secondary antibodies $(1.5: 10000)$. $\beta$-actin was used as a loading control. Membranes were scanned using the western lightning plus-ECL (Thermo Fisher Scientific). Signal intensities were quantified using ImageLab software.

\section{Fluorescence activated cell sorting (FACS)}

FACS analysis was performed to characterize effects of unacylated ghrelin on cell cycle and apoptosis. Cells were plated at a density of 500,000 cells in a $10 \mathrm{~cm} 2$ petri dish. Cells were serum-starved overnight with phenol red-free media and treated with different concentrations $(0-100 \mathrm{pM})$ of unacylated ghrelin, with or without $10 \mathrm{nM}$ estradiol. In order to determine effects on cell cycle, cells were treated for 5 days, with media being changed every 2 days. After 5 days, cells were harvested and fixed with ice cold $70 \%$ ethanol, stored overnight at $-20^{\circ} \mathrm{C}$, and stained with propidium iodine (PI) staining buffer ( $1 \mathrm{mg} / \mathrm{ml}$ RNase A, $0.1 \%$ Triton X-100, $100 \mu \mathrm{g} / \mathrm{ml} \mathrm{PI}$ in PBS). To evaluate effects on cell apoptosis, cells were treated for 6 hours, harvested and then stained with Annexin V-FITC for 15 min at room temperature in PBS. Cells were analysed with a FACSCANTO II flow cytometer (BD Biosciences, USA). For FACS data analysis by Flowjo software, forward scatter (FS) vs. side scatter (SS) plots were used for gating cells and to identify any changes in the scatter properties of the cells. Annexin V FITC-A vs Propidium lodide-A plots from the gated cells show the populations corresponding to viable and nonapoptotic (Annexin $\mathrm{V}-\mathrm{Pl}-$ ), early (Annexin $\mathrm{V}+\mathrm{PI}-$ ), and late (Annexin $\mathrm{V}+\mathrm{PI}+$ ) apoptotic cells.

\section{Analysis of cell cycle progression using the fluorescence ubiquitination cell} cycle indicator (FUCCI)

To investigate cell cycle progression and division in live cells, we used the fluorescent ubiquitination-based cell cycle indicator (FUCCI) to track the G1/G0 phase and S/G2/M phases. Breast cancer cells $(15 \times 104$ cells/well) in 6 wells plate were seeded in 2D and transduced with the Premo FUCCl Cell Cycle Sensor according to the manufacturer's protocol. After optimal expression of the FUCCI sensor was achieved ( $16 \mathrm{hr}$ ), cells were detached by TrypLE Express (Thermo Fisher Scientific), counted using a hemocytometer and seeded in media containing 30\% matrigel. Cells were serum-starved overnight, treated with $100 \mathrm{pM}$ unacylated ghrelin for 5 days with $10 \%$ serum and medium was replaced every 2 days. At endpoint, fluorescence was analyzed using confocal microscopy and cell counts obtained. Data are presented as a percentage of the total number of fluorescent cells examined.

\section{Xenograft and allograft studies}

One million MCF7 or ZR75 cells were injected into the mammary fat pad of 6-week old female athymic Balb/c nude (immunodeficient) mice. Estrogen pellets were prepared in the laboratory using $17 \beta$-estradiol (estrogen) powder and silicone according to previous publications (Laidlaw et al, 1995) and were implanted (0.8 mg/pellet, 60-day release) subcutaneously between the shoulder blades at the time of ER+ breast cancer cell injection. After injection, the mice were monitored daily for well-being, pain and distress, and for tumor growth by palpation. Tumors typically appeared within 14 days, with an engraftment rate of approximately $75 \%$. Once palpable, the tumors were measured daily in the long (L) and short $(\mathrm{W})$ axes with digital callipers, and tumor volume estimated using the standard formula (LxW2)/2. Once the tumor reached a volume of $200 \mathrm{~mm} 3$, the animal was randomized to receive saline (vehicle control) or unacylated ghrelin) via subcutaneous injection for a maximum of 28 days or until tumor size reached $10 \mathrm{~mm}$ in any axis, at which point the mice were humanely sacrificed by cervical dislocation. A syngeneic breast cancer mouse model was created in female FVB/N mice. $1.25 \times 105 \mathrm{~J} 110$ cells (obtained from Dr. Myles Brown) were injected into the mammary fat pad of 6-week old FVB (Immunocompetent) mice. Once the tumor reached a volume of $70 \mathrm{~mm} 3$, the mice were randomized to receive saline (vehicle control) or treatment (unacylated ghrelin or AZP531) via subcutaneous injection. After 7 days of treatment, the mice were humanely sacrificed by cervical dislocation. Additional studies were also performed in NSG mice. MDA-MB-468 $(1 \times 106)$ were injected into the mammary fat pad of 6-week old NSG (immunodeficient) mice. Once the tumor reached a volume of $150 \mathrm{~mm} 3$, the mice were randomized to receive saline (vehicle control) or AZP531 via subcutaneous injection. After 28 days of treatment, the mice were humanely sacrificed by cervical dislocation.

\section{Measurement of apoptotic cells from xenograft/allograft studies}

MCF7, ZR75 and J110 tumor sections post treatment with $100 \mu \mathrm{g} / \mathrm{kg}$ or $200 \mu \mathrm{g} / \mathrm{kg}$ of unacylated ghrelin were assessed using Hoechst nuclear stain and confocal microscopy. Quantification of cells with apoptotic nuclei was performed using Image $\mathrm{J}$. 


\section{Microarray datasets}

Gene expression profiles from GSE34412 were retrieved via GEO2R (https:// www.ncbi.nlm.nih.gov/geo/geo2r/). Expression profiles were based on a Custom Human Agilent array (GPL8269). GEO2R was used to perform differential gene expression analysis between responders (GSM847888, GSM847905) and non-responders (GSM847901, GSM847893). Ingenuity Pathway Analysis (IPA) was used to determine regulatory pathways that distinguished between responders and non-responders. Differences in gene expression were consistent with activation of upstream regulator MAPK1 in non-responders vs. responders (Z-score 3.888; overlap p-value 3.07E15), with 86 genes of 144 having measurements consistent with MAPK1 activation. Log expression values corresponding to the MAPK target genes were extracted from GEO2R for each sample. If a gene was represented by more than one probe, the expression value corresponding to the probe with the largest absolute fold-change between responders and non-responders was selected. Genes predicted by IPA to be activated were visualized in a heatmap (expression values were centered and scaled).

\section{Statistical analysis}

All experiments were performed at least twice with $n=3$ per experiment and all data are expressed as the mean \pm SEM. Statistical analysis was carried out with software Graph Pad Prism 7. For experiments with multiple comparisons, statistical analysis was performed using one-way ANOVA followed by Dunnett multiple comparison, where means of each column were compared to the mean of a control column. For experiments with two independent groups comparisons, statistical analysis was performed using two-way ANOVA followed by Dunnett multiple comparison, where means of each cell were compared to the control cell mean on that row. A p-value was reported and significance was classified as $p<0.05(*), p \leq 0.005(* *), p \leq$ $0.0005\left(^{* * *}\right), \mathrm{p} \leq 0.0001(* * *)$.

\section{Data Availability}

This study did not generate/analyze datasets or code.

\section{REFERENCES}

Allas, S., Caixas, A., Poitou, C., Coupaye, M., Thuilleaux, D., Lorenzini, F., Diene, G., Crino, A., Illouz, F., Grugni, G., et al. (2018). AZP-531, an unacylated ghrelin analog, improves food-related behavior in patients with Prader-Willi syndrome: A randomized placebo-controlled trial. PLoS One 13, e0190849.

Allas, S., Delale, T., Ngo, N., Julien, M., Sahakian, P., Ritter, J., Abribat, T., and van der Lely, A.J. (2016). Safety, tolerability, pharmacokinetics and pharmacodynamics of AZP-531, a first-in-class analogue of unacylated ghrelin, in healthy and overweight/obese subjects and subjects with type 2 diabetes. Diabetes Obes Metab 18, 868-874.

Aronica, S.M., Kraus, W.L., and Katzenellenbogen, B.S. (1994). Estrogen action via the CAMP signaling pathway: stimulation of adenylate cyclase and cAMP-regulated gene transcription. Proc Natl Acad Sci U S A 91, 8517-8521.

Au, C.C., Docanto, M.M., Zahid, H., Raffaelli, F.M., Ferrero, R.L., Furness, J.B., and Brown, K.A. (2017). Des-acyl ghrelin inhibits the capacity of macrophages to stimulate the expression of aromatase in breast adipose stromal cells. J Steroid Biochem Mol Biol 170, 49-53.

Au, C.C., Furness, J.B., and Brown, K.A. (2016). Ghrelin and Breast Cancer: Emerging Roles in Obesity, Estrogen Regulation, and Cancer. Front Oncol 6, 265.

Benso, A., St-Pierre, D.H., Prodam, F., Gramaglia, E., Granata, R., van der Lely, A.J., Ghigo, E., and Broglio, F. (2012). Metabolic effects of overnight continuous infusion of unacylated ghrelin in humans. Eur J Endocrinol 166, 911-916.

Callaghan, B., and Furness, J.B. (2014). Novel and conventional receptors for ghrelin, desacyl-ghrelin, and pharmacologically related compounds. Pharmacol Rev 66, 984-1001.

Callaghan, B., Hunne, B., Hirayama, H., Sartor, D.M., Nguyen, T.V., Abogadie, F.C., Ferens, D., McIntyre, P., Ban, K., Baell, J., et al. (2012). Sites of action of ghrelin receptor ligands in cardiovascular control. Am J Physiol Heart Circ
Physiol 303, H1011-1021.

Cassoni, P., Papotti, M., Ghe, C., Catapano, F., Sapino, A., Graziani, A., Deghenghi, R., Reissmann, T., Ghigo, E., and Muccioli, G. (2001). Identification, characterization, and biological activity of specific receptors for natural (ghrelin) and synthetic growth hormone secretagogues and analogs in human breast carcinomas and cell lines. J Clin Endocrinol Metab 86, 1738-1745.

Chen, J., Bander, J.A., Santore, T.A., Chen, Y., Ram, P.T., Smit, M.J., and lyengar, R. (1998). Expression of Q227L-galphas in MCF-7 human breast cancer cells inhibits tumorigenesis. Proc Natl Acad Sci U S A 95, 2648-2652.

Cho-Chung, Y.S., Clair, T., Bodwin, J.S., and Berghoffer, B. (1981). Growth arrest and morphological change of human breast cancer cells by dibutyryl cyclic AMP and L-arginine. Science 214, 77-79.

Docanto, M.M., Yang, F., Callaghan, B., Au, C.C., Ragavan, R., Wang, X., Furness, J.B., Andrews, Z.B., and Brown, K.A. (2014). Ghrelin and des-acyl ghrelin inhibit aromatase expression and activity in human adipose stromal cells: suppression of cAMP as a possible mechanism. Breast Cancer Res Treat $147,193-201$

Fajardo, A.M., Piazza, G.A., and Tinsley, H.N. (2014). The role of cyclic nucleotide signaling pathways in cancer: targets for prevention and treatment. Cancers (Basel) 6, 436-458.

Fontana, J.A., Miksis, G., Miranda, D.M., and Durham, J.P. (1987). Inhibition of human mammary carcinoma cell proliferation by retinoids and intracellular cAMP-elevating compounds. J Natl Cancer Inst 78, 1107-1112.

Gangadhara, S., Smith, C., Barrett-Lee, P., and Hiscox, S. (2016). 3D culture of Her2+ breast cancer cells promotes AKT to MAPK switching and a loss of therapeutic response. BMC Cancer 16, 345.

Giltnane, J.M., and Balko, J.M. (2014). Rationale for targeting the Ras/MAPK pathway in triple-negative breast cancer. Discov Med 17, 275-283.

Gordge, P.C., Hulme, M.J., Clegg, R.A., and Miller, W.R. (1996). Elevation of protein kinase $\mathrm{A}$ and protein kinase $\mathrm{C}$ activities in malignant as compared with normal human breast tissue. Eur J Cancer 32A, 2120-2126.

Gronberg, M., Fjallskog, M.L., Jirstrom, K., and Janson, E.T. (2012). Expression of ghrelin is correlated to a favorable outcome in invasive breast cancer. Acta Oncol 51, 386-393.

Hipfner, D.R., and Cohen, S.M. (2004). Connecting proliferation and apoptosis in development and disease. Nat Rev Mol Cell Biol 5, 805-815.

Kim, R.K., Suh, Y., Yoo, K.C., Cui, Y.H., Kim, H., Kim, M.J., Gyu Kim, I., and Lee, S.J. (2015). Activation of KRAS promotes the mesenchymal features of basal-type breast cancer. Exp Mol Med 47, e137.

Kung, W., Roos, W., and Eppenberger, U. (1983). Growth stimulation of human breast cancer MCF-7 cells by dibutyryl cyclic AMP. Cell Biol Int Rep 7, 345-351.

Lonning, P.E., and Eikesdal, H.P. (2013). Aromatase inhibition 2013: clinical state of the art and questions that remain to be solved. Endocr Relat Cancer 20, R183-201.

Minton, J.P., Wisenbaugh, T., and Matthews, R.H. (1974). Elevated cyclic AMP levels in human breast-cancer tissue. J Natl Cancer Inst 53, 283-284.

Nonaka, M., Kurebayashi, N., Murayama, T., Sugihara, M., Terawaki, K., Shiraishi, S., Miyano, K., Hosoda, H., Kishida, S., Kangawa, K., et al. (2017). Therapeutic potential of ghrelin and des-acyl ghrelin against chemotherapyinduced cardiotoxicity. Endocr J 64, S35-S39.

Noone, A.M., Howlader, N., Krapcho, M., Miller, D., Brest, A., Yu, M., Ruhl, J., Tatalovich, Z., Mariotto, A., Lewis, D.R., et al. (2018). SEER Cancer Statistics Review, 1975-2015 (Bethesda, MD: National Cancer Institute). 
Au et al, Unacylated ghrelin and AZP531 suppress the 3D growth of breast cancers - preprint

O'Leary, B., Finn, R.S., and Turner, N.C. (2016). Treating cancer with selective CDK4/6 inhibitors. Nat Rev Clin Oncol 13, 417-430.

Reinert, T., and Barrios, C.H. (2015). Optimal management of hormone receptor positive metastatic breast cancer in 2016. Ther Adv Med Oncol 7, 304-320.

Santen, R.J., Song, R.X., McPherson, R., Kumar, R., Adam, L., Jeng, M.H., and Yue, W. (2002). The role of mitogen-activated protein (MAP) kinase in breast cancer. J Steroid Biochem Mol Biol 80, 239-256.

Tian, Y.F., Ahn, H., Schneider, R.S., Yang, S.N., Roman-Gonzalez, L., Melnick, A.M., Cerchietti, L., and Singh, A. (2015). Integrin-specific hydrogels as adaptable tumor organoids for malignant B and T cells. Biomaterials 73, 110119.

Tilch, E., Seidens, T., Cocciardi, S., Reid, L.E., Byrne, D., Simpson, P.T., Vargas, A.C., Cummings, M.C., Fox, S.B., Lakhani, S.R., et al. (2014). Mutations in EGFR, BRAF and RAS are rare in triple-negative and basal-like breast cancers from Caucasian women. Breast Cancer Res Treat 143, 385-392.
Weigelt, B., Ghajar, C.M., and Bissell, M.J. (2014). The need for complex 3D culture models to unravel novel pathways and identify accurate biomarkers in breast cancer. Adv Drug Deliv Rev 69-70, 42-51.

Zhang, W., Chai, B., Li, J.Y., Wang, H., and Mulholland, M.W. (2008). Effect of des-acyl ghrelin on adiposity and glucose metabolism. Endocrinology 149, 4710-4716.

Zhang, X., Claerhout, S., Prat, A., Dobrolecki, L.E., Petrovic, I., Lai, Q., Landis, M.D., Wiechmann, L., Schiff, R., Giuliano, M., et al. (2013). A renewable tissue resource of phenotypically stable, biologically and ethnically diverse, patient-derived human breast cancer xenograft models. Cancer Res 73, 4885-4897. 
bioRxiv preprint doi: https://doi.org/10.1101/2020.01.22.915744; this version posted January 23, 2020. The copyright holder for this preprint (which was not certified by peer review) is the author/funder, who has granted bioRxiv a license to display the preprint in perpetuity. It is made available under aCC-BY-NC-ND 4.0 International license.

Au et al, Unacylated ghrelin and AZP531 suppress the 3D growth of breast cancers - preprint

A

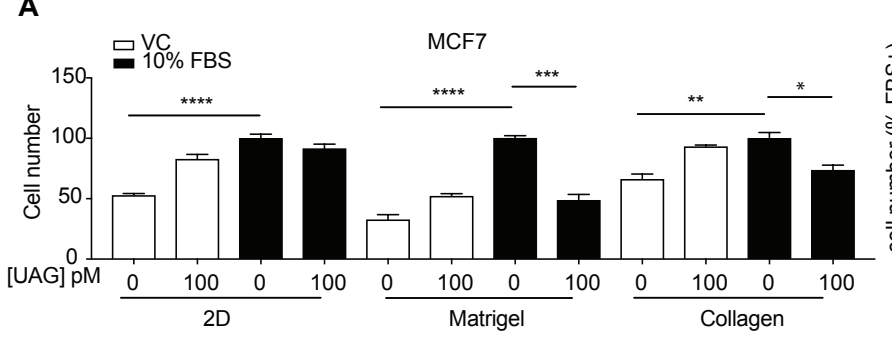

B

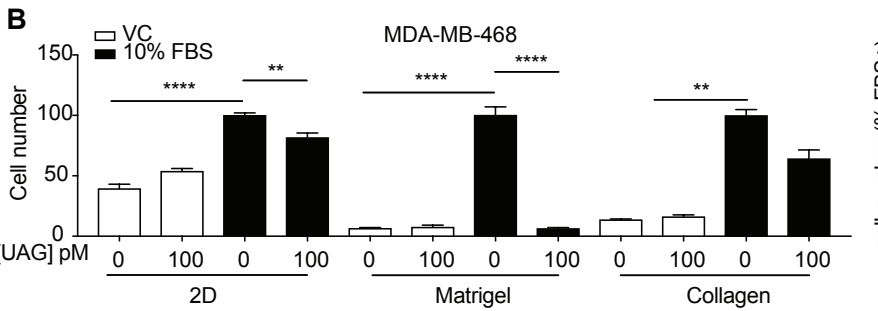

C

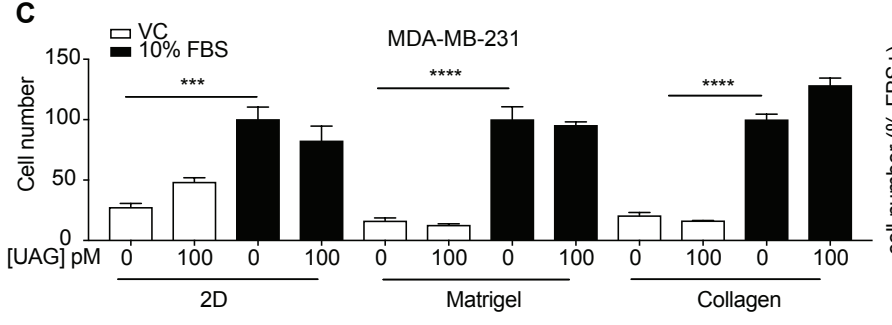

D
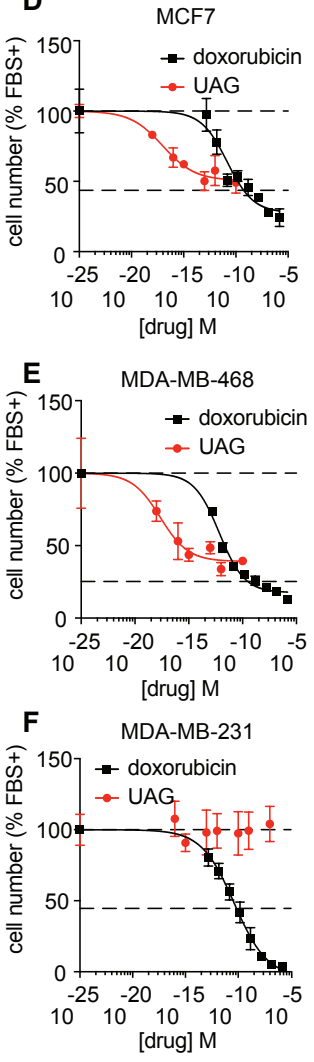

G

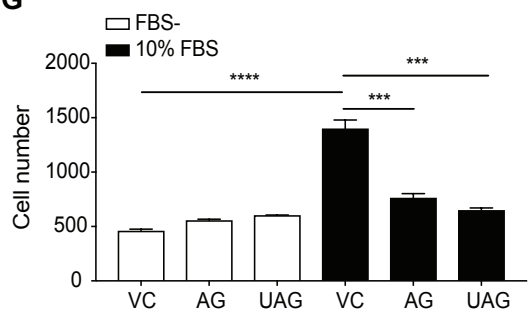

H

MCF7

MDA-MB-468 MDA-MB-231

0
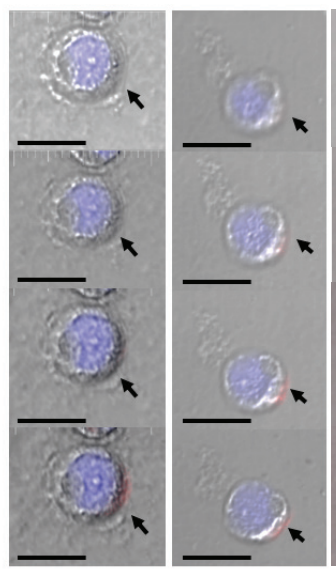

Figure S1. Unacylated ghrelin (UAG) inhibits the growth of breast cancer cells in 3D. Related to Figure 1. UAG (100pM) inhibits the growth of (A) MCF7 and (B) MDA-MB-468 grown in 3D in matrigel or collagen, but not in 2D. (C) UAG had no effect on MDA-MB-231 cell growth in 2D or 3D. Dose-dependent effects of UAG and doxorubicin on the growth of (D) MCF7, (E) MDA-MB-468 and (F) MDA-MB-231 cells in 3D. (G) Acyl ghrelin (AG) and UAG (100pM) inhibit breast cancer cell growth in serum-stimulated conditions. (H) Binding of Cy3-labelled UAG to MCF7, MDA-MB-468 and MDA-MB-231 cells, representative image. Scale bar represents $20 \mu \mathrm{m}$. Data represent mean \pm SEM with $\mathrm{n} \geq 3$. Experiments repeated at least twice. UAG: unacylated ghrelin; AG: acylated ghrelin; VC: vehicle control; FBS: fetal bovine serum 
bioRxiv preprint doi: https://doi.org/10.1101/2020.01.22.915744; this version posted January 23, 2020. The copyright holder for this preprint (which was not certified by peer review) is the author/funder, who has granted bioRxiv a license to display the preprint in perpetuity. It is made available under aCC-BY-NC-ND 4.0 International license.

Au et al, Unacylated ghrelin and AZP531 suppress the 3D growth of breast cancers - preprint

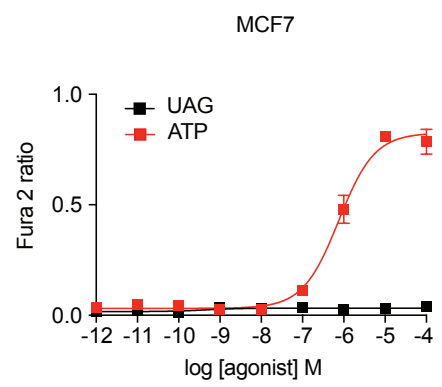

C

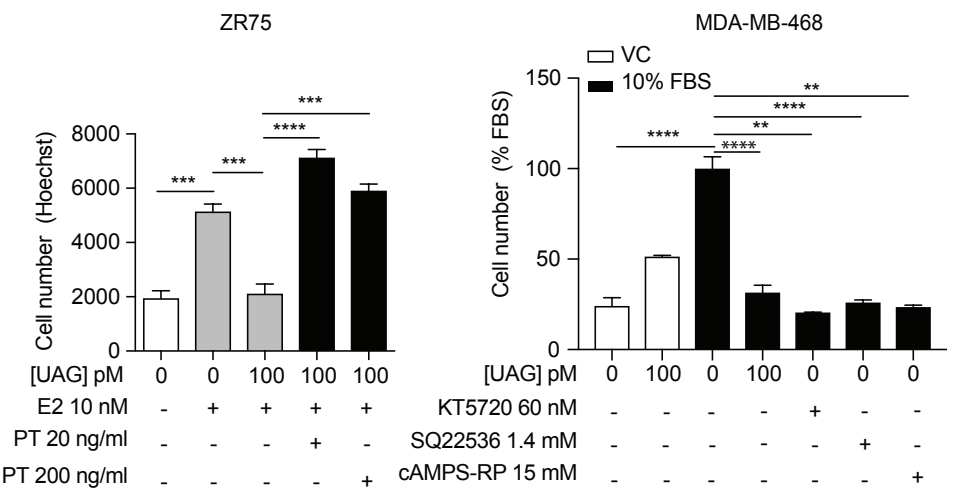

B

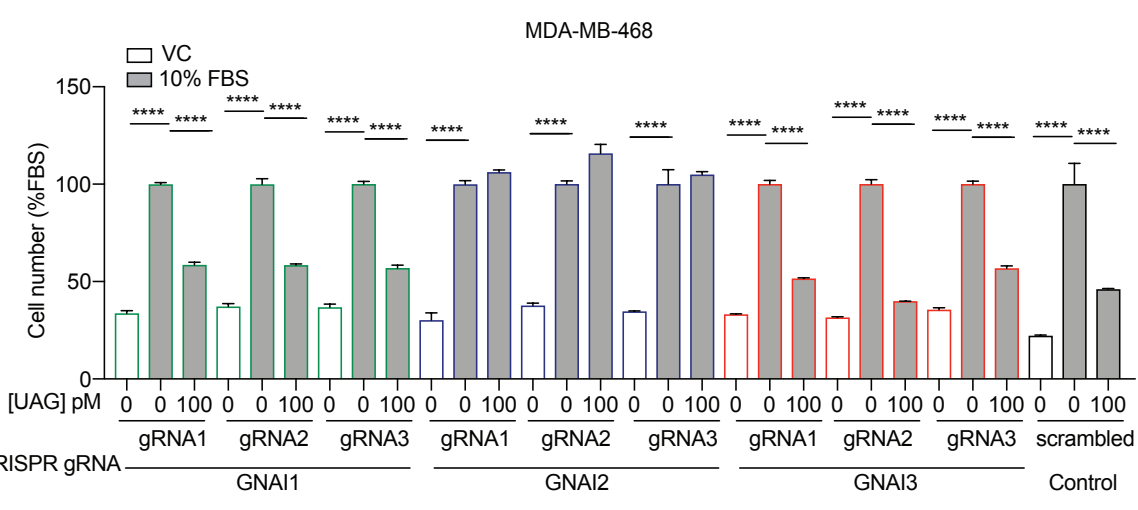

E

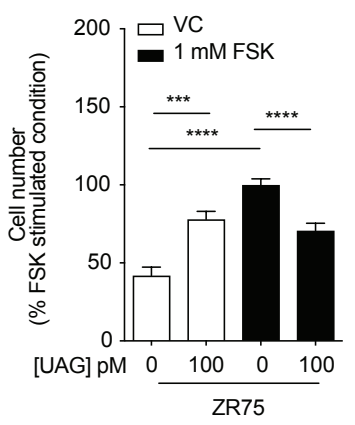

$\mathbf{F}$

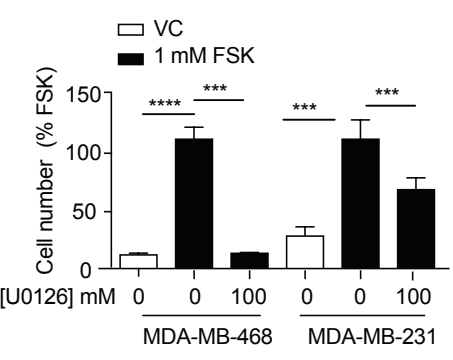

G

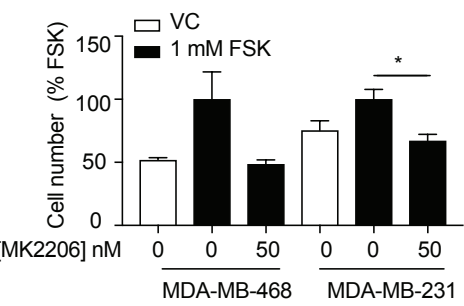

Figure S2. Unacylated ghrelin (UAG) suppresses breast cancer cell growth via Gai-dependent.mechanisms. Related to Figure 2. (A) UAG has no effect on the release of intracellular Ca2+ in MCF7 cells. (B) UAG (100pM) suppresses the growth of MDA-MB-468 CRISPR GNAI1 and GNAI3 KO cells, but not CRISPR GNAI2 KO cells, suggesting that UAG effects are via a GNAI2-coupled GPCR. (C) Suppression of estradiol-stimulated ZR75 cell growth by UAG (100pM) is prevented by Gai inhibitor, pertussis toxin (20ng/ml, 200ng/ml). (D) PKA (KT5720) or adenylyl cyclase (SQ22536) inhibitors, or cAMP antagonist (cAMPS-RP) suppress the growth of MDA-MB-468 cells. (E) UAG (100pM) inhibits the forskolin-stimulated ZR75 cell growth, while (F) U0126 (MEK inhibitor) and (G) MK2206 (Akt inhibitor) inhibit the forskolin-stimulated growth of MDA-MB-468 and MDA-MB-231 cells. Data represent mean \pm SEM with $\mathrm{n} \geq 3$. Experiments repeated at least twice. UAG: unacylated ghrelin; FBS: fetal bovine serum; E2: estradiol; FSK: forskolin. 
bioRxiv preprint doi: https://doi.org/10.1101/2020.01.22.915744; this version posted January 23, 2020. The copyright holder for this preprint (which was not certified by peer review) is the author/funder, who has granted bioRxiv a license to display the preprint in perpetuity. It is made available under aCC-BY-NC-ND 4.0 International license.

A

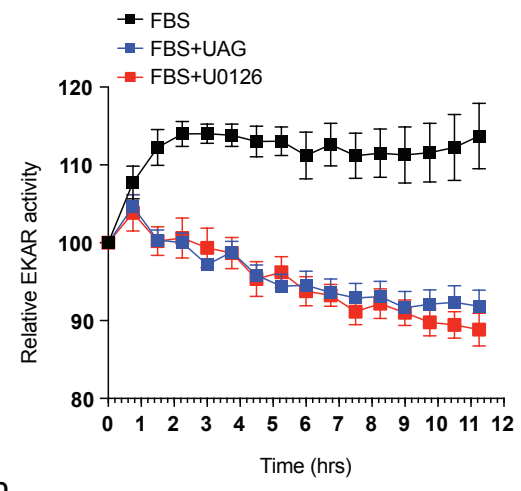

D

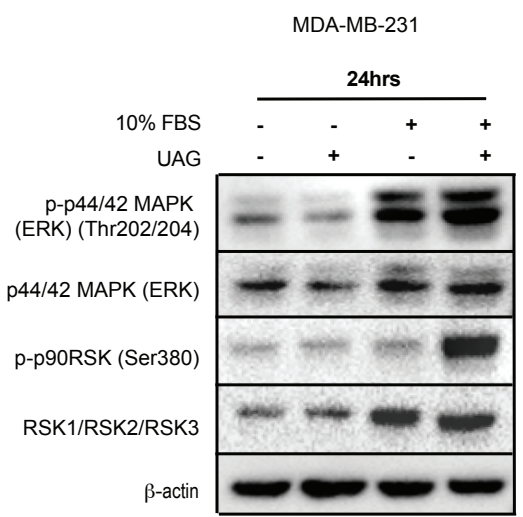

I

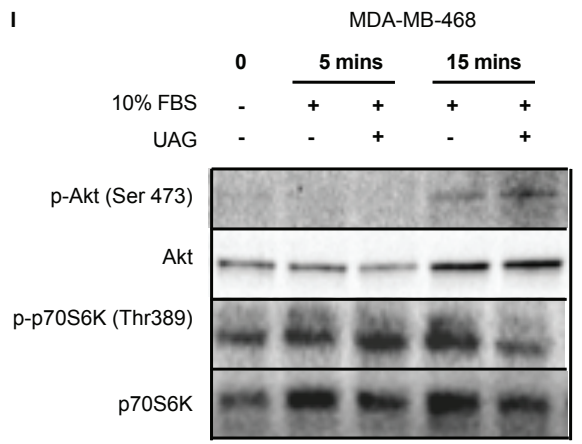

$\mathbf{L}$

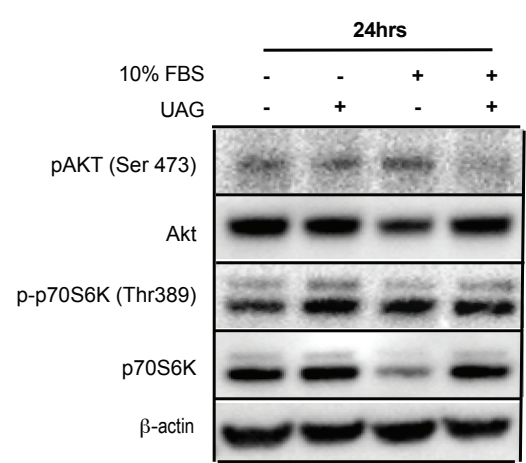

Au et al, Unacylated ghrelin and AZP531 suppress the 3D growth of breast cancers - preprint

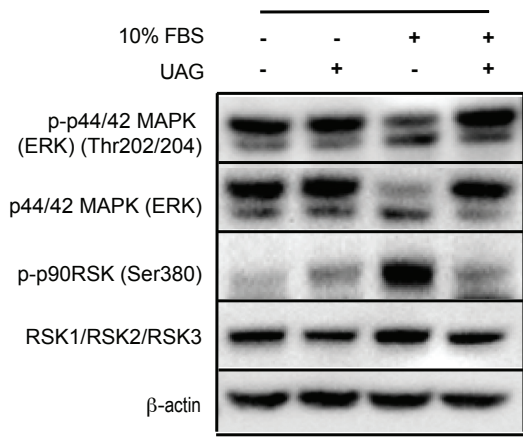

$E$

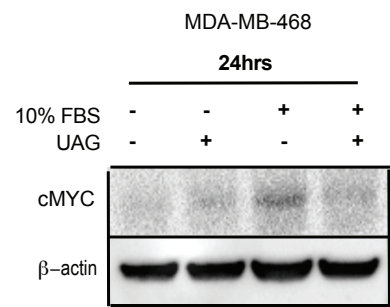

$\mathbf{F}$
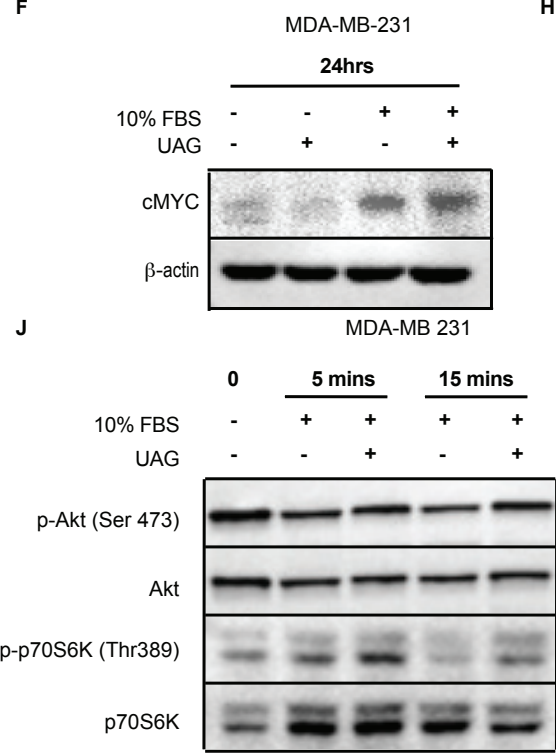

M
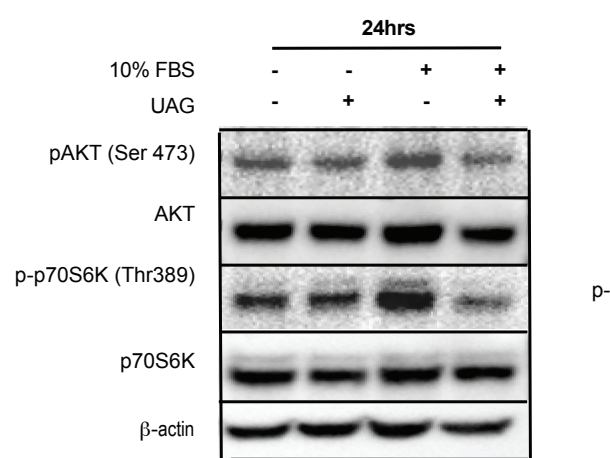

G

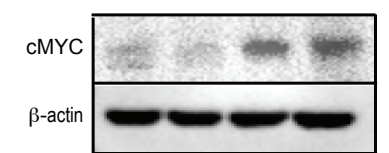

K

$\mathbf{N}$
C
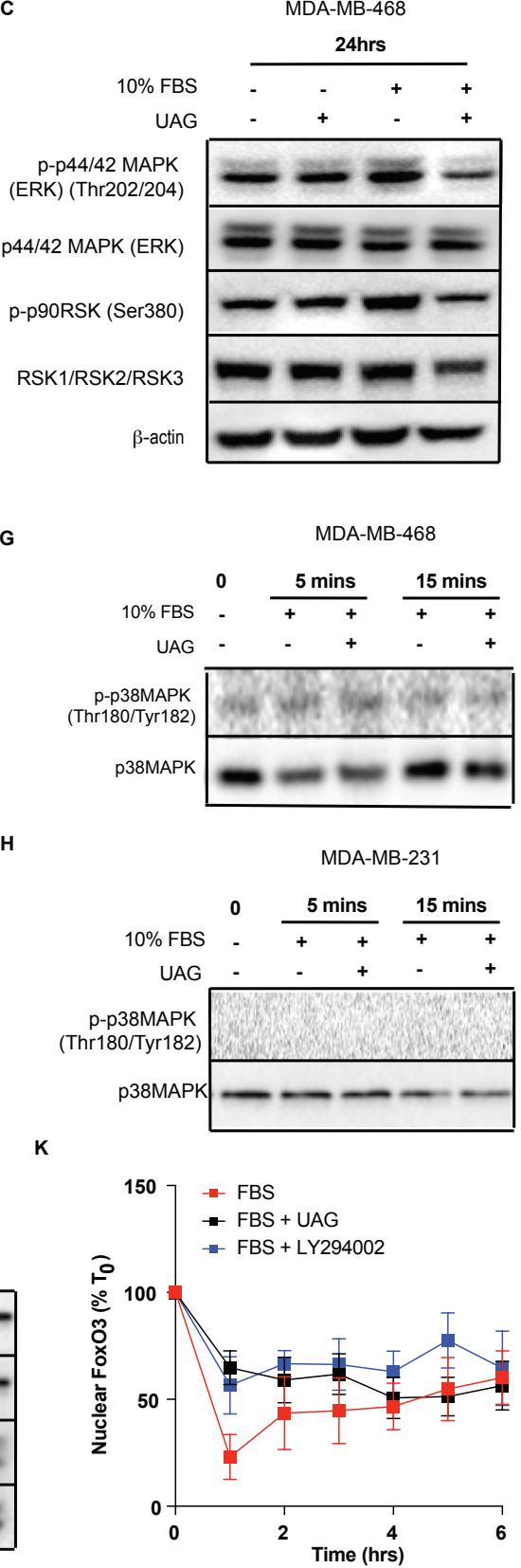

MDA-MB-231
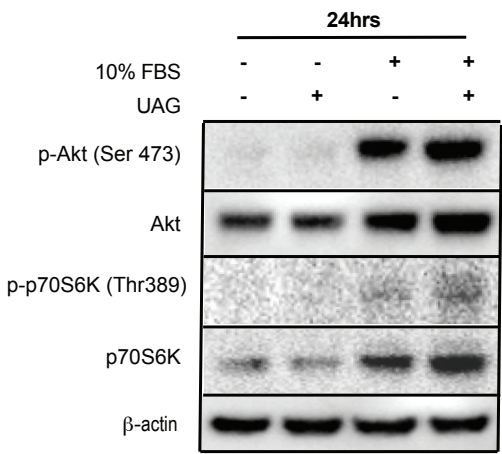

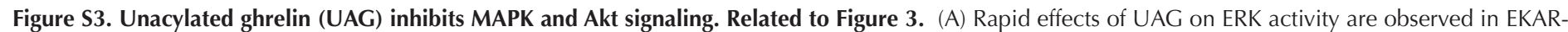

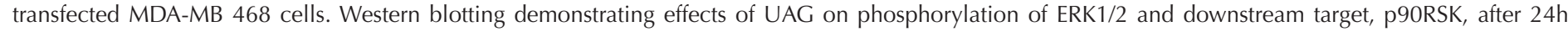

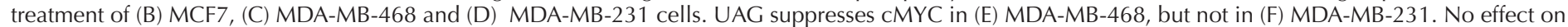

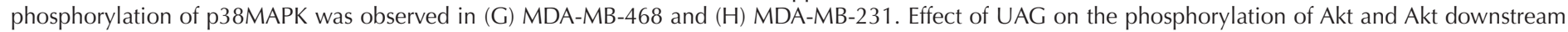

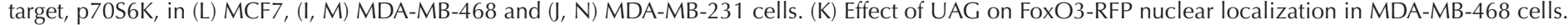
Data represent mean \pm SEM with $n \geq 3$. Experiments were repeated at least twice. UAG: unacylated ghrelin; FBS: fetal bovine serum 
bioRxiv preprint doi: https://doi.org/10.1101/2020.01.22.915744; this version posted January 23, 2020. The copyright holder for this preprint (which was not certified by peer review) is the author/funder, who has granted bioRxiv a license to display the preprint in perpetuity. It is made available under aCC-BY-NC-ND 4.0 International license.

Au et al, Unacylated ghrelin and AZP531 suppress the 3D growth of breast cancers - preprint

A LCC2
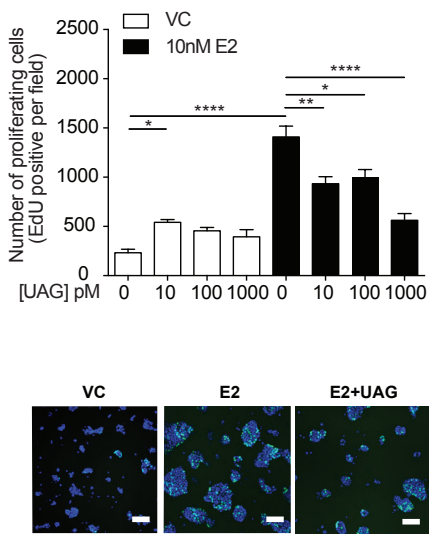
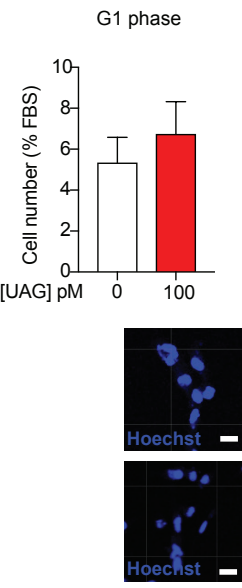

MDA-MB-231
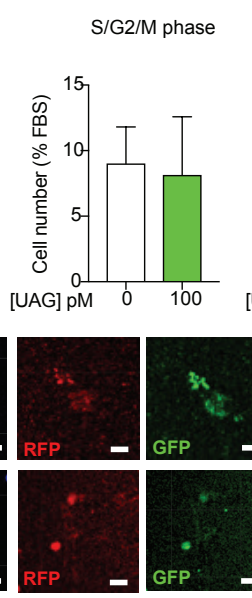

MDA-MB-231

G1/S transition
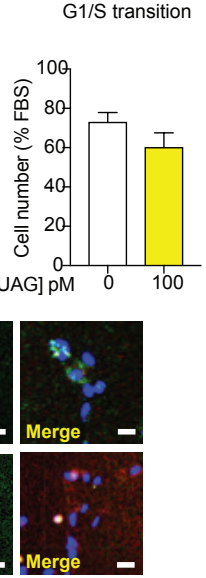

$\begin{array}{rrrrr}10 \% \text { FBS } & - & - & + & + \\ \text { UAG } & - & + & - & +\end{array}$

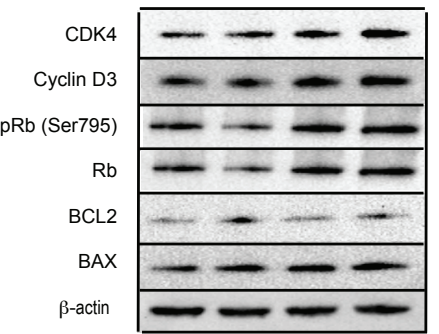

E

D

MCF7
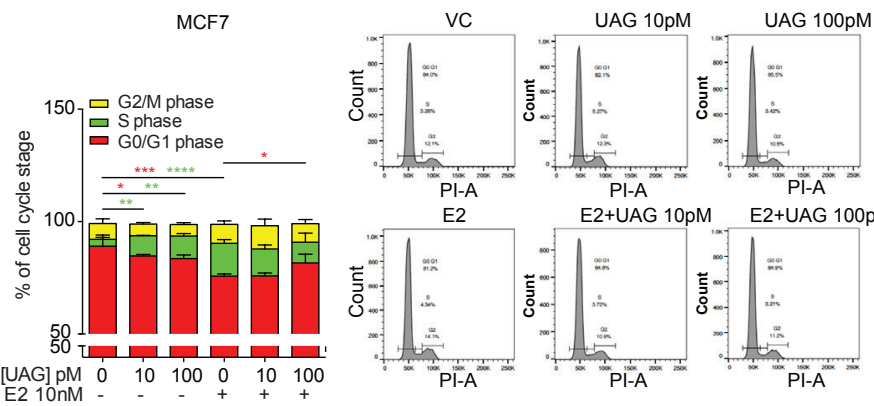

E2+UAG 10pM E2+UAG 100pM
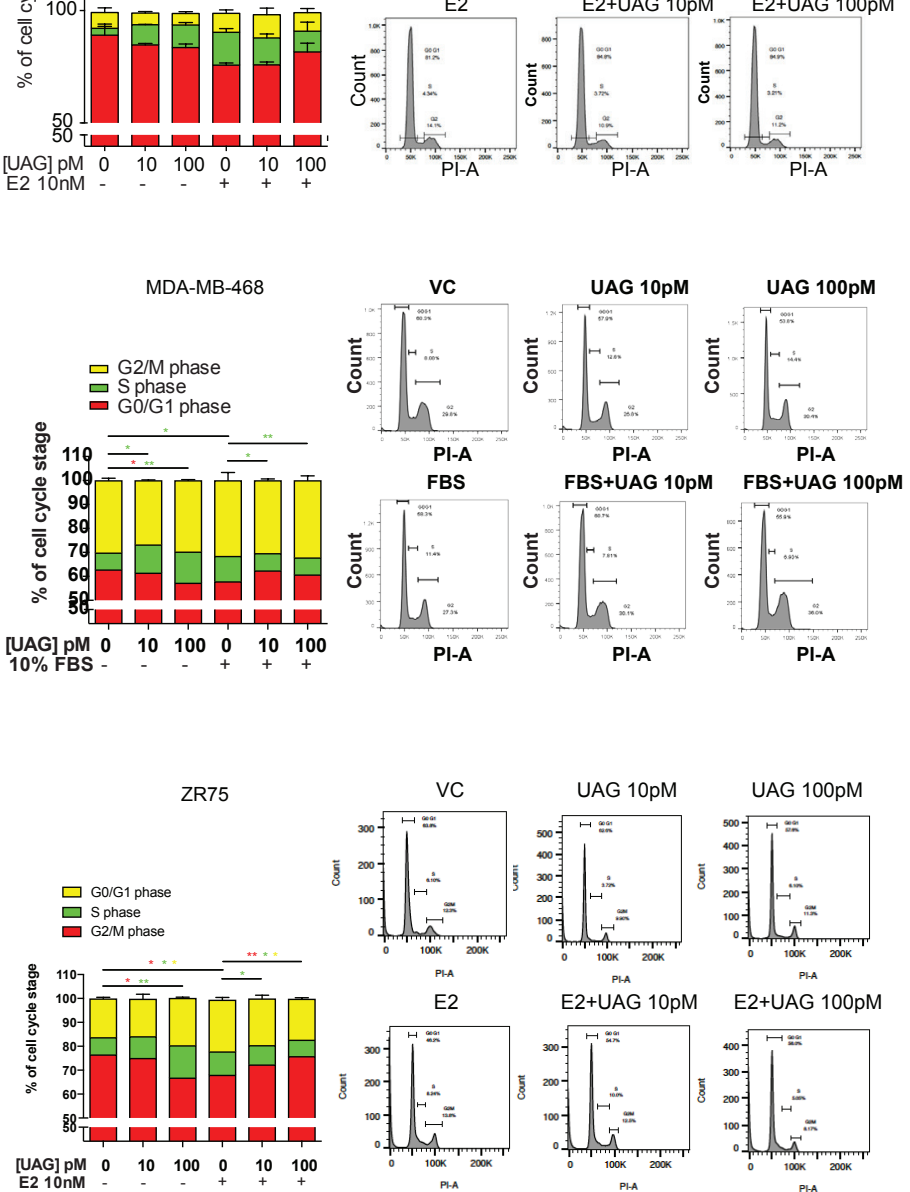
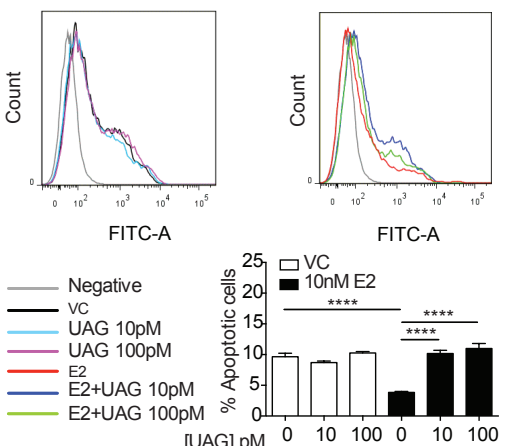

[UAG] pM $0 \begin{array}{llllll}10 & 100 & 0 & 10 & 100\end{array}$
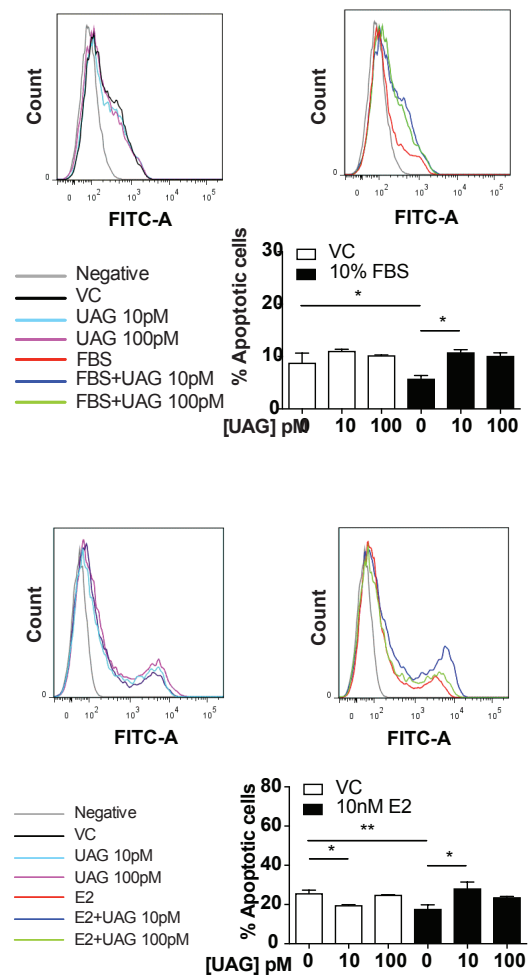

Figure S4. Unacylated ghrelin (UAG) causes cell cycle arrest and apoptosis. Related to Figure 4. (A) UAG significantly inhibits the proliferation of LCC2 tamoxifen-resistant cells in the presence of estradiol (10nM). Representative images showing EdU incorporation (green). (Hoechst nuclear stain; blue). Scale bar represent $100 \mu \mathrm{m}$. (B) No effects of UAG on MDA-MB-231 cell cycle were observed when using FUCCI cell cycle system. (C) Unacylated ghrelin had no effect on CDK4/cyclin D3, pRB (Ser 795), BCL2, cMYC or BAX in MDA-MB-231 cells. Flow cytometry analysis demonstrating that UAG induces G1-phase cell cycle arrest and apoptosis in (D, E) MCF7, $(F, G)$ MDA-MB-468 and $(H, I) Z R 75$, respectively. Data represent mean \pm SEM with $n \geq 3$. Experiments repeated at least twice. UAG: unacylated ghrelin; FBS: fetal bovine serum; E2: estradiol. 
bioRxiv preprint doi: https://doi.org/10.1101/2020.01.22.915744; this version posted January 23, 2020. The copyright holder for this preprint (which was not certified by peer review) is the author/funder, who has granted bioRxiv a license to display the preprint in perpetuity. It is made available under aCC-BY-NC-ND 4.0 International license.

Au et al, Unacylated ghrelin and AZP531 suppress the 3D growth of breast cancers - preprint

A

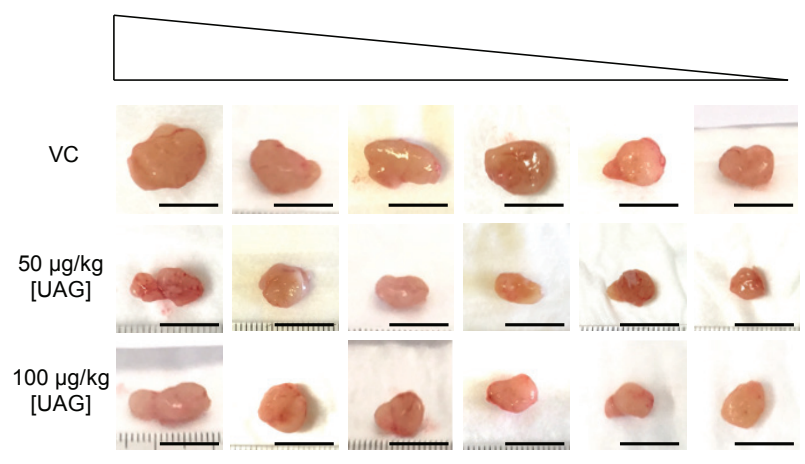

C

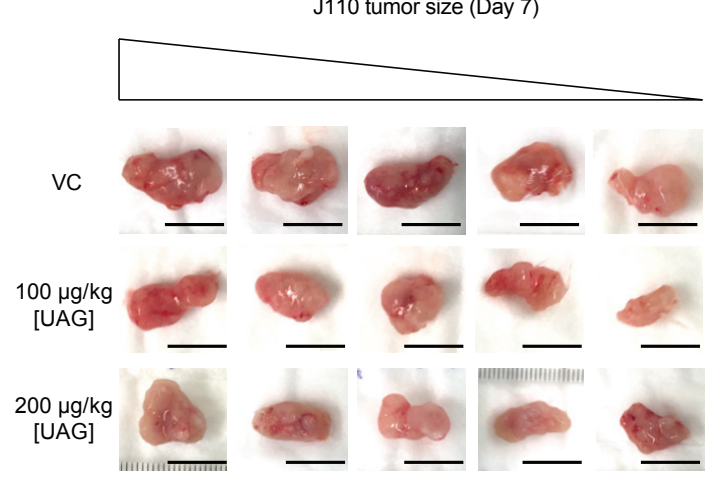

$\mathbf{F}$

MDA-MB-468 tumor size (Day 28)
B

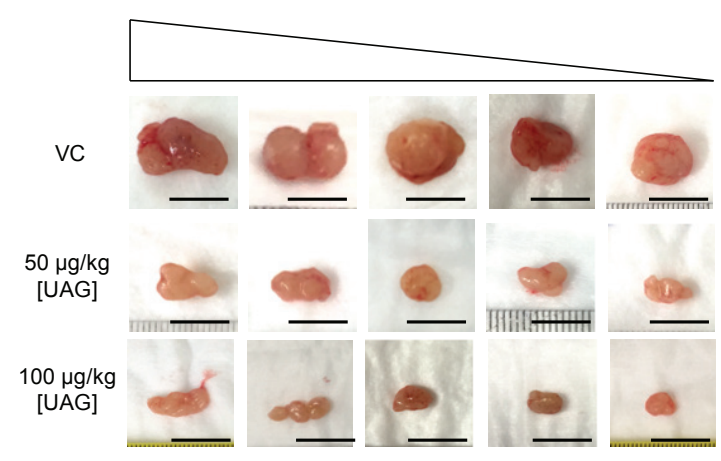

E
D

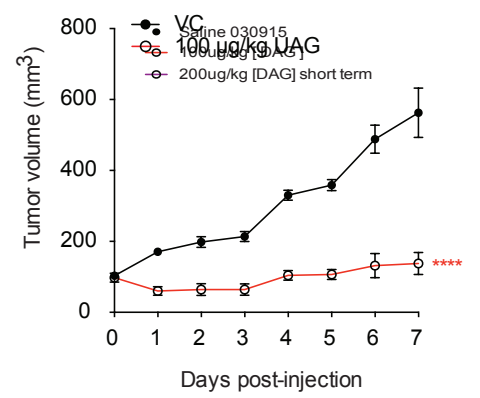

G

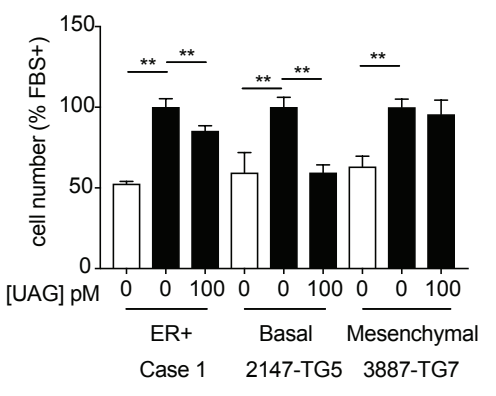

J110 tumor size (Day 7)

VC
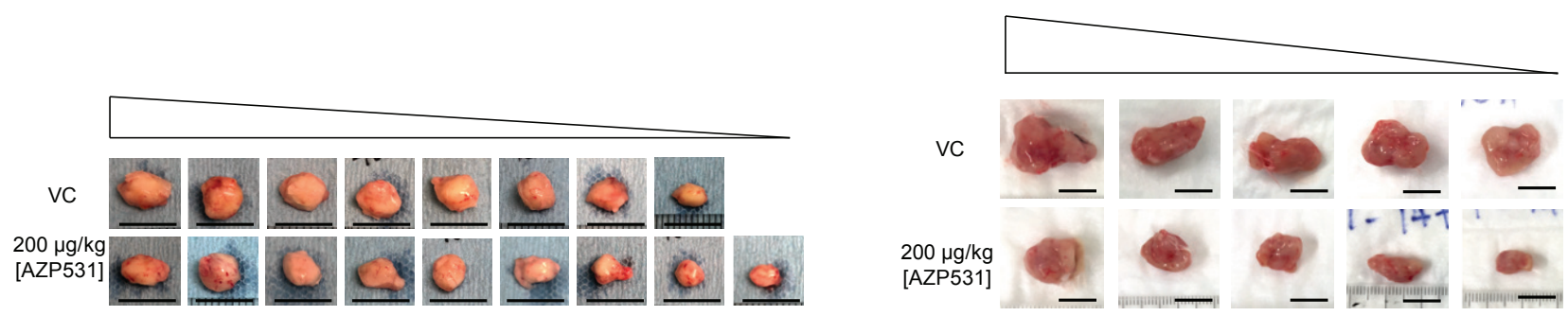

Figure S5. Unacylated ghrelin (UAG) and cyclic analog AZP531 inhibit tumor growth in xenograft models and patient-derived tumor cells. Related to Figure 5 and 6. Representative image of tumor in response to treatment with $50 \mu \mathrm{g} / \mathrm{kg}$ or $100 \mu \mathrm{g} / \mathrm{kg}$ UAG in nude mice xenografted with (A) MCF7 ( $\mathrm{n}=6 / \mathrm{group}$ ) and (B) ZR75 ( $n=5$ /group) cells. Effect of UAG on tumor volume of J110 ( $n=5 /$ group) (C) allografts in FVB mice or (D) xenografts in nude mice compared to vehicle control. (E) UAG (100pM) significantly inhibited the growth of patient-derived ER+ breast cancer, basal-like (BL) TNBC, but the growth of a mesenchymal (M)

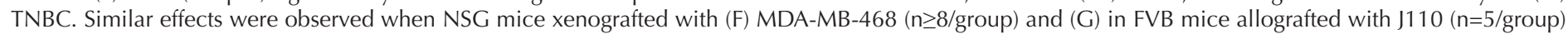
cells were treated with $200 \mu \mathrm{g} / \mathrm{kg}$ AZP531. Scale bar represents $10 \mathrm{~mm}$. Data represent mean \pm SEM with $\mathrm{n} \geq 3$. Experiments repeated at least twice. UAG: unacylated ghrelin; VC: vehicle control. 
bioRxiv preprint doi: https://doi.org/10.1101/2020.01.22.915744; this version posted January 23, 2020. The copyright holder for this preprint (which was not certified by peer review) is the author/funder, who has granted bioRxiv a license to display the preprint in perpetuity. It is made available under aCC-BY-NC-ND 4.0 International license.

Au et al, Unacylated ghrelin and AZP531 suppress the 3D growth of breast cancers - preprint
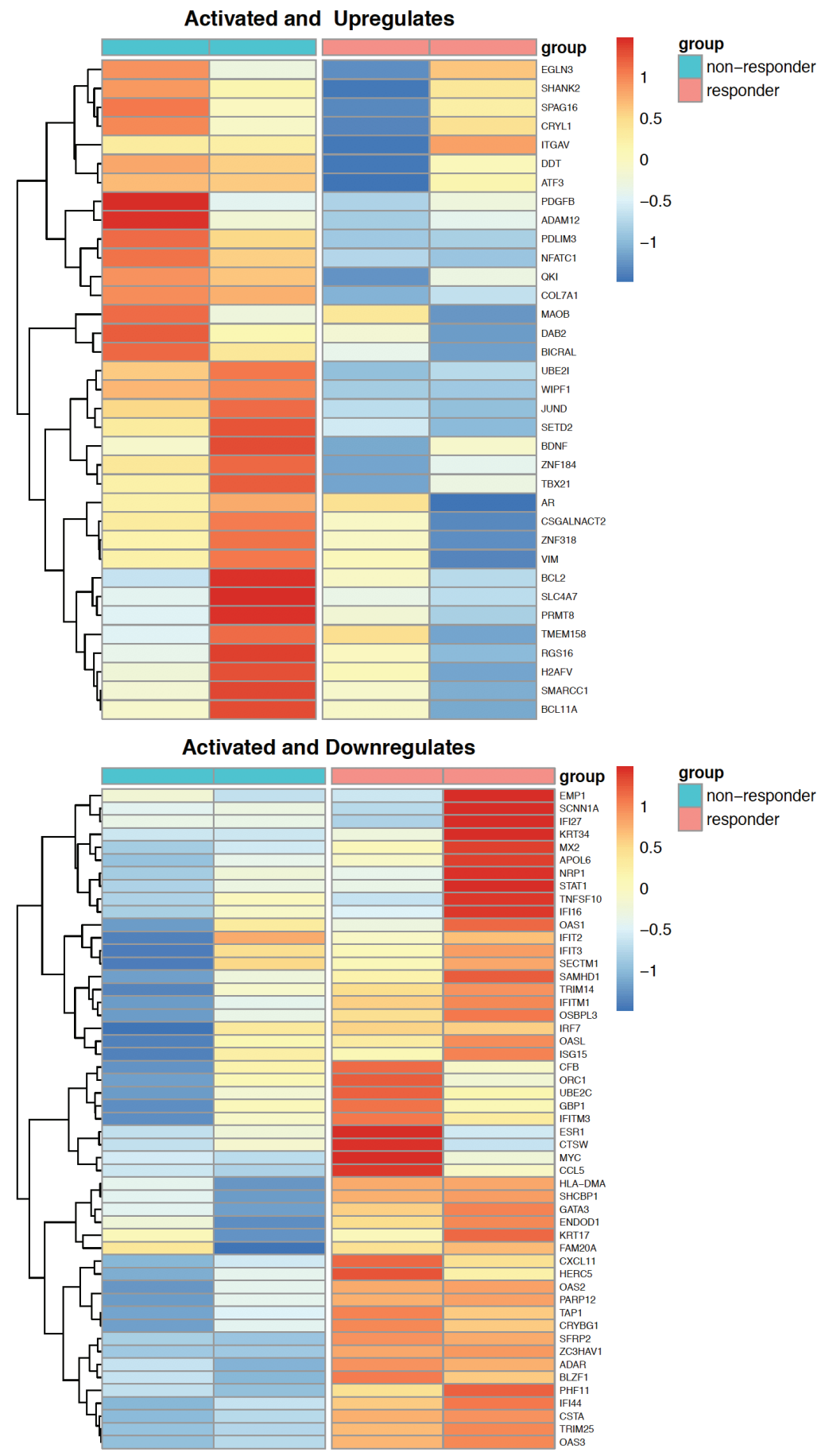

Figure S6. Expression pattern of MAPK-target genes in responder and non-responder TNBC patient-derived breast cancer cases. Related to Figure 5. Red and blue colors indicate high and low gene expression, respectively. 
Table 1. Characteristics of breast cancer cell lines and patient-derived breast cancer cells, and responsiveness to unacylated ghrelin.

\begin{tabular}{|c|c|c|c|c|}
\hline $\begin{array}{l}\text { Breast cancer } \\
\text { cell line/ Patient } \\
\text { sample }\end{array}$ & Known mutations & Intrinsic subtype & Receptor Status & $\begin{array}{l}\text { Responsive to } \\
\text { Unacylated } \\
\text { Ghrelin }\end{array}$ \\
\hline \multicolumn{5}{|l|}{ Cell line } \\
\hline MCF7 & CDKN2A, PIK3CA & Luminal A & $\mathrm{ER}^{+} / \mathrm{PR}^{+} / \mathrm{HER} 2^{-}$ & Yes \\
\hline $\mathrm{LCC} 2$ & N/A & Luminal A & $\mathrm{ER}^{+} / \mathrm{PR}^{+} / \mathrm{HER} 2^{-}$ & Yes \\
\hline T47D & PIK3CA, TP53 & Luminal A & $\mathrm{ER}^{+} / \mathrm{PR}^{+} / \mathrm{HER} 2^{-}$ & Yes \\
\hline ZR75 & PTEN & Luminal B & $\mathrm{ER}^{+} / \mathrm{PR}^{+} / \mathrm{HER} 2^{+}$ & Yes \\
\hline SKBR3 & TP53 & HER 2+ & $\mathrm{HER}^{+}$ & Yes \\
\hline MDA-MB 468 & $\begin{array}{l}\text { PTEN, RB1, SMAD4, } \\
\text { TP53 }\end{array}$ & Basal-like & TNBC & Yes \\
\hline MDA-MB 157 & NF1, TP53 & Mesenchymal-like & TNBC & Yes \\
\hline MDA-MB 231 & $\begin{array}{l}\text { BRAF, KRAS, TP53, } \\
\text { CDKN2A, NF2 }\end{array}$ & Mesenchymal-like & TNBC & No \\
\hline HS578T & HRAS, TP53 & Mesenchymal-like & TNBC & No \\
\hline DU4475 & $\begin{array}{l}\text { BRAF,APC, MAP2K4, } \\
\text { RB1 }\end{array}$ & Basal-like & TNBC & No \\
\hline \multicolumn{5}{|l|}{ Patient samples } \\
\hline $\mathrm{ER}^{+}$Case 1 & N/A & Luminal A & $\mathrm{ER}^{+}$ & Yes \\
\hline $\mathrm{ER}^{+}$Case 2 & $\mathrm{~N} / \mathrm{A}$ & Luminal A & $\mathrm{ER}^{+}$ & Yes \\
\hline 2147-TG5 & N/A & Basal-like & TNBC & Yes \\
\hline 4013-TG3 & N/A & Basal-like & TNBC & Yes \\
\hline 3887-TG7 & N/A & Mesenchymal-like & TNBC & No \\
\hline 3204-TG6 & N/A & Mesenchymal-like & TNBC & No \\
\hline
\end{tabular}

Abbreviations: ER, estrogen receptor; PR, progesterone receptor; HER2, human epidermal growth factor receptor 2; TNBC, triple negative breast cancer; N/A: not available 